\title{
Toxic volatile organic air pollutants across Canada: multi-year concentration trends, regional air quality modelling and source apportionment
}

\author{
Craig A. Stroud ${ }^{1}$ - Calin Zaganescu ${ }^{2}$ - Jack Chen ${ }^{2,3}$. \\ Chris A. McLinden ${ }^{1}$ • Junhua Zhang ${ }^{1}$ - Danny Wang ${ }^{4}$
}

Received: 4 May 2015 / Accepted: 25 September 2015 /

Published online: 8 October 2015

(C) The Author(s) 2015. This article is published with open access at Springerlink.com

\begin{abstract}
A Unified Regional Air-quality Modelling System, AURAMS, was expanded to predict six toxic volatile organic compounds (VOCs) within a continental domain and two nested domains covering eastern and western Canada. The model predictions were evaluated against Environment Canada's National Air Pollution Surveillance (NAPS) data set to assess the predictive capability of the model at daily and seasonal time scales. The predictions were also evaluated with satellite-derived column total maps for formaldehyde, carbon monoxide, and nitrogen dioxide. In general, the model showed fair to good predictive skill in terms of both correlation $(\mathrm{R})$ and normalized mean bias $(\mathrm{NMB})$ for benzene $(\mathrm{R}=0.53 \mathrm{NMB}=26 \%)$, formaldehyde $(\mathrm{R}=0.73, \mathrm{NMB}=-15 \%)$ and acetaldehyde $(\mathrm{R}=0.55, \mathrm{NMB}=29 \%)$. For the other toxics VOCs, the model showed less predictive skill in the order 1,2,4-trimethylbenzene $(\mathrm{R}=0.50, \mathrm{NMB}=-41 \%), 1,3$-butadiene $(\mathrm{R}=0.26, \mathrm{NMB}=40 \%)$ and acrolein $(\mathrm{R}=0.052$, $\mathrm{NMB}=-51 \%$ ). The goal of this study was to apply an air quality model to assess the contribution of mobile sources to ambient levels of toxic VOCs at urban locations across Canada. The mobile source contribution varied in a complex manner for each species for different regions. For benzene and 1,2,4-trimethylbenzene, the mobile source contribution was in the range $40-65 \%$ for major Canadian cities. The model predicted considerably lower
\end{abstract}

Electronic supplementary material The online version of this article (doi:10.1007/s10874-015-9319-z) contains supplementary material, which is available to authorized users.

Craig A. Stroud

craig.stroud@ec.gc.ca

1 Air Quality Modelling and Integration Section, Air Quality Research Division, Science and Technology Branch, 4905 Dufferin Street, Toronto, ON M3H5T4, Canada

2 Air Quality Modelling and Application Section, Meteorological Service of Canada, Dorval, QC H9P1J3, Canada

3 Now at Canadian Ice Services, Meteorological Service of Canada, Ottawa, ON K1A 0H3, Canada

4 Air Quality Measurements and Analysis, Air Quality Research Division, Science and Technology Branch, Ottawa, ON K1A 0H3, Canada 
mobile source contributions for rural locations in the Canadian Prairies, where other area sources dominate, such as the petrochemical industry. Measured concentration trends in toxics are also presented from 2004 to 2010 . The primary emitted toxics declined gradually (13-16\% over 6 yr) whereas the toxic aldehydes showed no trend.

Keywords Global environmental multiscale (GEM) model · Air quality · Smog · Toxics · Mobile emissions $\cdot$ Hazardous air pollutants (HAPs) $\cdot$ A unified regional air-quality modelling system (AURAMS)

\section{Introduction}

The Canadian Environment Protection Act established a list of toxic air pollutants that are of potential concern to the public in terms of ambient air exposure (CEPA 1999, Schedule 1). Environment Canada and Health Canada are mandated to develop and implement regulations to control their release into the environment. With support from the Clean Air Regulatory Agenda and Health Canada, Environment Canada developed a project to improve air quality modelling capabilities for several toxic volatile organic compounds (VOCs). The six toxic VOCs studied here are benzene, 1,3-butadiene, 1,2,4-trimethylbenzene, formaldehyde, acetaldehyde and acrolein. This is by no means an exhaustive list, as other classes of compounds are also considered under CEPA (e.g. ozone, metals, PCBs, PAHs). Information on source apportionment for each toxic VOC would be useful to support environmental assessments, especially the impact of mobile sources on human outdoor air exposures in cities.

Many previous studies have used Gaussian plume dispersion models to predict ambient air concentrations (Heist et al. 2013). These models are useful for calculating the exposure to directly emitted pollutants near individual point sources; however these models simplify the atmospheric chemistry for species and do not typically consider long-range transport. Several toxic VOCs are photochemically produced in the atmosphere (e.g. formaldehyde) and require detailed precursor VOC emissions and modelled oxidant concentrations. Many of the toxic VOCs also have longer lifetimes (e.g. benzene). Eulerian chemical transport models are therefore a better tool at predicting the toxic VOCs over a wide model domain via inclusion of processes impacting toxic VOCs over their lifetime. The domains can be continental in scale and can include nested domains down to finer grid spacings. Previous modelling studies for toxic VOCs, performed by the U.S. EPA, have used the Community Multiscale Air Quality (CMAQ) chemical transport model (Luecken et al. 2006; Luecken et al. 2012). Environment Canada has also used AURAMS to model toxic PAHs across North America (Galarneau et al. 2014). Benzo-[a]-pyrene (BaP) predictions are of particular interest; however, more model development is needed, as the Galarneau et al. evaluation shows that AURAMS significantly over-predicts $\mathrm{BaP}$.

In this work, we describe the modification and application of Environment Canada's AURAMS model to simulate toxic VOCs across Canada over the winter and summer seasons for base year 2006. Here, we focus on describing the emissions processing and the gas-phase chemical mechanism. The results section includes model evaluation against available observations for the toxic VOCs, as well as for ozone and nitrogen dioxide. In the model evaluation section, we will also explore newly developed model evaluation techniques provided by satellite observations. We will perform a source apportionment analysis comparing the relative proportions of primary emission sources (mobile and other emissions) and the relative 
contributions of primary sources and secondary chemistry production. Finally, the multi-year trends in ambient toxic VOC observations will be studied to assess whether emission reduction strategies have been effective at reducing risk between 2004 and 2010.

\section{Methods}

\subsection{Measurement program}

The Environment Canada National Air Pollution Surveillance (NAPS) network is a coast-to-coast monitoring program with approximately 50 sites measuring toxic hydrocarbons (benzene, 1,3-butadiene and 1,2,4-trimethylbenzene), 15 sites measuring formaldehyde and acetaldehyde and 6 sites measuring acrolein for 2006. Figure S1 shows the locations of the NAPS sites reporting toxic VOCs on a map of Canada. Approximately three quarters are in densely populated areas and one quarter in sparsely populated areas. The densely populated sites are characterized in the NAPS network as urban commercial and urban residential. The sparely populated sites are defined as forest, agricultural, or barren. Some sites are also defined as industrial, but can be in populated or sparsely populated areas. Sites were sampled one day every three or six days, depending on the site and season. The urban sites sample for 24-h and rural sites for 4-h in the afternoon.

\subsection{Sampling protocol}

The hydrocarbon species were sampled into evacuated stainless steel canisters and returned to Environment Canada for analysis by gas chromatography and mass spectrometry detection (Curren et al. 2006). The polar aldehyde species were sampled into cartridges filled with a dinitrophenylhydrazine (DNPH) coated adsorbent for derivatization of the aldehyde functional group. The cartridges were returned to Environment Canada for analysis by high performance liquid chromatography and ultraviolet absorption detection (US EPA Method 8315A). The detection limits for the hydrocarbons and aldehydes were approximately $25 \mathrm{pptv}$ and $50 \mathrm{pptv}$, respectively.

\subsection{Regional air quality model description}

In this work, we used a unified regional air modelling system (acronym AURAMS), which has been developed by Environment Canada over the past two decades for air quality forecasting and policy-related emission scenario applications (Rouleau et al. 2013). A detailed model description for AURAMS can be found in a series of previous publications: advection (Côté et al. 1998), emissions (Makar et al. 2003b), gas-phase chemistry (Stroud et al. 2008), aerosol microphysics (Gong et al. 2003) and equilibrium partitioning (Makar et al. 2003a), cloud processing (Gong et al. 2011), secondary organic aerosol parameterization (Stroud et al., 2011). A recent comparison of AURAMS, GEM-MACH, WRF-CMAQ and WRF-CHEM can be found in Makar et al., (Makar et al. 2014a, b).

Here, we applied AURAMS v1.5.1 on a 45-km grid-spaced continental domain covering North America (not the Arctic) with $143 \times 107$ grid points. The grid had 28 vertical layers with a lowest layer depth of 7.5-m and a lid in the upper troposphere. We also used two nested grids, one for western Canada $(124 \times 93$ points $)$ and one for eastern Canada $(145 \times 123$ 
points), each with 22.5-km grid spacing. Figure S2 shows the two nested sub-domains and the outer domain. The outer domain provides the lateral boundary conditions for the nested domains, which is particularly important for the eastern sub-domain. This configuration enabled an assessment of the impact of model grid spacing on toxic VOC predictions (see section 3.4). Meteorological inputs to AURAMS were provided by Environment Canada's weather forecast model, GEM v3.3.2, with a native $15-\mathrm{km}$ grid spacing for a continental domain encompassing the AURAMS domain. Simulations were performed for two 4-month periods, summer and winter 2006, and each includes a 1-month spin-up period. Chemical boundary conditions were prepared for the outer domain from ozonesonde measurements, satellite observations and ground measurements at Whistler, along the West Coast of British Columbia (MacDonald et al. 2011). Ozone boundary conditions make use of a monthly 3-D climatology (Logan 1999). CO and $\mathrm{PM}_{2.5}$ boundary conditions are simplified profiles based on satellite observations (MOPITT and MODIS) with seasonal and latitudinal variations (Kelly et al. 2012). The benzene at the boundaries is derived from proton-transfer reaction mass spectrometry observations from Whistler with seasonal variations. Short-lived chemical tracers and toxics have constant low concentration profiles on the outer domain boundaries. Vertical turbulent diffusion and mixing was parameterized in AURAMS with modified K-theory, solved with the Laasonen numerical method (Richtmyer 1994). Vertical diffusivity coefficients are imported into AURAMS from the GEM weather forecast model. Lower limits to the pollutant vertical diffusivities $\left(0.1 \mathrm{~m}^{2} / \mathrm{s}\right)$ were included to simulate the sub-grid scale mechanical mixing processes. The relative impact of such lower limits is discussed in detail in Makar et al. (2014c).

\subsection{Emissions}

Model emissions were created using the 2005 US National Emission Inventory and the 2006 Canadian National Pollutant Release Inventory (NPRI). Model-ready emissions were prepared using the U.S. EPA SMOKE program version 2.4 with the U.S. EPA SPECIATE version 4.3 VOC speciation profiles. Mobile emissions in Canada were generated using the MOBILE 6.2C program modified for Canadian weather conditions and vehicle fleet distributions. The toxic VOC species in MOBILE6.2C were modelled explicitly with fuel-specific (e.g. after treatment technology) and condition-specific (e.g. temperature and driving cycle) emission factors. Non-road mobile emissions are calculated with EPA's NONROAD tool (http://www. epa.gov/OTAQ/emission-factors-research/index.htm). The toxic VOC emissions are reported directly to NPRI for the major point source facilities. The reporting can be at a fine temporal resolution, but there is considerable uncertainty, as they are based on periodic source testing and published emission factors (relative to total VOC) and with standard temporal profiles for each month and day of week. Area emission files (e.g. home heating and food cooking sources) were prepared on an hourly basis and are specific to day of week and month. The quality of the area emissions varies from largely source to source. The U.S. EPA SPECIATE database gives a rating from 1 to 5 (previous versions, 5 is highest quality) or from A to $\mathrm{E}$ (latest version, A is highest quality) for listed source profiles (http://www.epa.gov/ttnchie1/ software/speciate/) Biogenic emissions were modelled with the US EPA's BEIS model v3.09 with modifications to the BELD3 land use maps for Canadian forests surveys and more recent satellite imagery (Stroud et al. 2008). The more detailed biogenic VOC emission speciation in BEIS v3.12 was used to map biogenic emissions to the expanded chemical mechanism (SAPRC-07 toxics, see below) used in AURAMS. Recently, Cahill (2014) reviewed the potential emission sources for acrolein. 
Figure 1 presents the 2006 Canadian NPRI emissions on a percentage mass emitted by sector basis, for each of the 6 toxic VOCs studied. Benzene had the largest national emission total of the 6 species studied at $81 \mathrm{kt} / \mathrm{yr}$. The oil and gas sector contributed the largest percentage at $55 \%$, by mass, for benzene and includes emissions for petrochemical refining, petrochemical solvent storage, transport and off-road heavy-duty diesel use, such as heavy hauler diesel vehicles used in the Canadian oil sands. The area, industrial and on-road mobile sectors contributed between 10 to $16 \%$. Area sources for benzene include household heating, agricultural activities, solvent usage, and waste disposal burning. Natural biomass burning was not included in the emission inventories used here. The industrial sector includes upstream petrochemical, printing, chemical manufacturing, and pulp and paper. The 1,2,4-trimethylbenzene emissions were dominated by the marine/air/rail sector (55\%) followed by the oil and gas sector (18\%). The 1,3-butadiene emissions from the marine/air/rail $(47 \%)$ and other miscellaneous area $(24 \%)$ sectors were the largest contributors. The three aldehyde species have large area and industrial emission sources and lower emissions from the
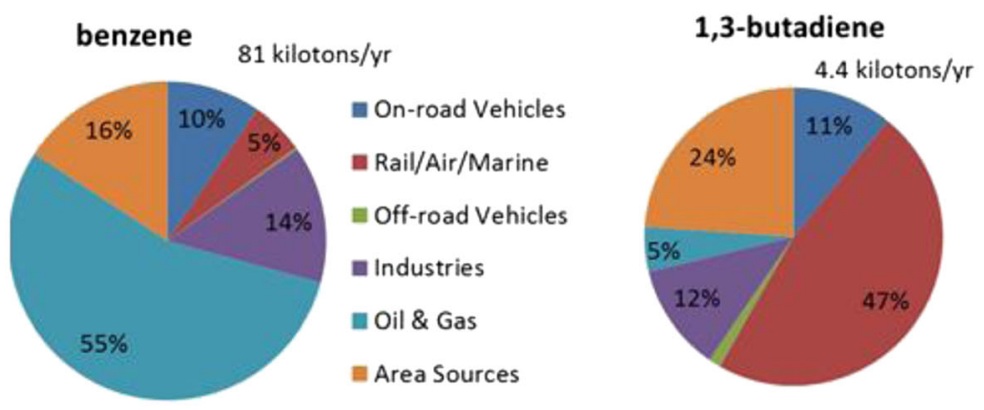

\section{1,2,4-trimethylbenzene}
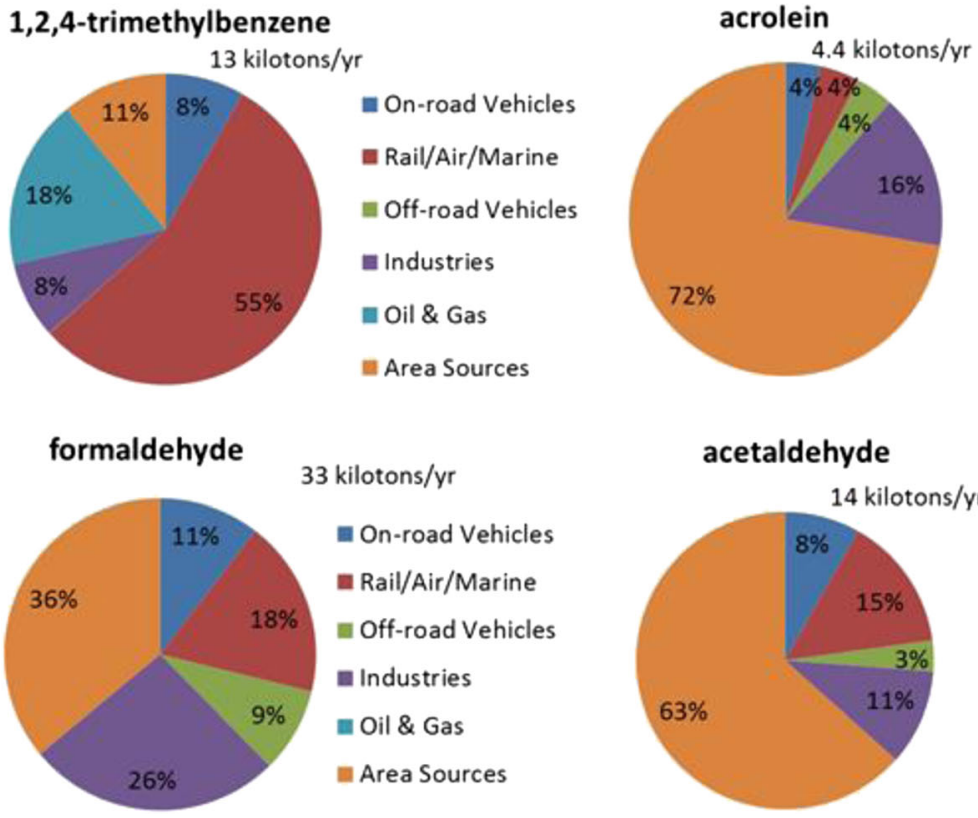

acetaldehyde

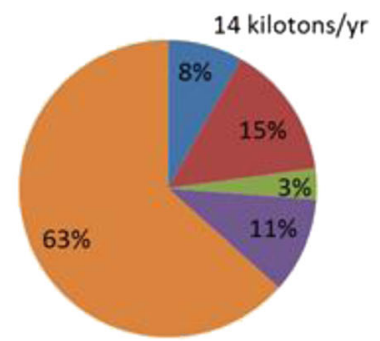

Fig. 1 The 2006 Canadian NPRI emission sector contributions for each of the 6 toxic VOCs studied, as percentages 
oil and gas sector compared to the hydrocarbons studied. However, the secondary production of aldehydes from biogenic and anthropogenic hydrocarbons can also be important over determining air mixing ratios (see section 3.4).

\subsection{Chemistry}

The SAPRC-07 gas-phase chemical mechanism has been documented in Carter (2010) and its performance diagnosed in Hutzell et al. (2012) for the Community Multi-scale Air Quality (CMAQ) model. This study uses the SAPRC-07 toxics version, which includes explicit chemical speciation for the six toxics species studied here. In total, there are 136 chemical species and 601 reactions. The mechanism was implemented in the Kinetic PreProcessor (KPP), which generated the Fortran90 code that was implemented into AURAMS (in the place of the standard ADOM-II gas-phase reaction mechanism and the Young and Boris (1977) chemical solver). KPP offers several options for a chemical solver method and here we chose the Rosenbrock method due to its combination of accuracy and speed (Sandu and Sander 2006). The standard chemical mechanism in AURAMS includes a parameterization to calculate photolysis rates as a function of grid cell altitude, solar zenith angle and cloud coverage fraction. The $\mathrm{O}_{3}$ and $\mathrm{NO}_{2}$ photolysis rates are common to both chemical mechanisms. Here, the $\mathrm{NO}_{2}$ photolysis rate was used as the common species to scale the other photolysis rates in the SAPRC-07 toxics mechanism. A standard reference table for all the photolysis species in SAPRC-07 toxics was used (Carter 2010) to calculate photolysis rates ratios relative to the $\mathrm{NO}_{2}$ photolysis rate.

\subsection{Satellite measurements and comparisons with AURAMS}

Summertime measurements (June-August 2006) from the Ozone Monitoring Instrument (OMI) and Measurement Of Pollutants in The Troposphere (MOPITT) satellite instruments are used to evaluate the AURAMS spatial distributions of $\mathrm{HCHO}, \mathrm{NO}_{2}$, and CO. OMI, 2004-present, is a Dutch/Finnish nadir-viewing UV-visible spectrometer on the NASA Aura satellite that provides measurements of tropospheric $\mathrm{HCHO}$ and $\mathrm{NO}_{2}$ tropospheric vertical column densities (VCDs) (Levelt et al. 2006). MOPITT, 1999-present, is a Canadian xxx on the NASA Terra satellite and provides measurements of CO VCDs (Drummond and Mand 1996).

The Dutch-OMI-NO $\mathrm{NO}_{2}$ (DOMINO) version $2 \mathrm{NO}_{2}$ (Boersma et al. 2011; http://www.temis. $\mathrm{nl} /$ airpollution/no2.html) and the Belgian Institute for Space Aeronomy (BIRA) version 17 HCHO (De Smedt et al. 2008, 2012; http://h2co.aeronomie.be/) VCDs are filtered for radiative cloud fraction (maximum 0.3), solar zenith angle (maximum $70^{\circ}$ ), snow (snow-free only), and pixel size (only track positions 11-50 are considered). The period under consideration predates the onset of the OMI row anomaly so this was not an issue. The version 6 joint thermalnear IR CO (Deeter et al. 2014; https://www2.acd.ucar.edu/mopitt) VCDs are filtered according to cloud conditions (cloud-free conditions only), solar zenith angle (maximum $75^{\circ}$ ), snow (snow-free only), and degrees-of-freedom-for-signal $(>1)$. Comparisons are made by first matching each satellite measurement with a spatially and temporally coincident AURAMS profile. This approach minimizes the effect of satellite sampling on the comparison which can lead to, for example, clear-sky biases.

In the case of $\mathrm{NO}_{2}$ and $\mathrm{HCHO}$, air mass factors were recalculated using the AURAMS vertical profile according to the methodology of McLinden et al. (2014). These were then applied to the OMI measurements and were paired with the AURAMS VCDs obtained by 
vertically integrating the number density profiles. For $\mathrm{CO}$, the MOPITT the total column averaging kernel was applied to the AURAMS profile. These were vertically integrated and paired with the MOPITT CO VCDs. All satellite and AURAMS profiles over the three month period were then averaged on the AURAMS horizontal grid.

\section{Results and discussion}

\subsection{Multi-year trends in observations}

The NAPS observation data set described above was analyzed to look at the trends in the six toxic VOCs between 2004 and 2010, as 3-month seasonal averages using data from all the sites across Canada (Figs. 2 and 4) and as annual averages at specific cities (Figs. 3 and 5). All three toxic hydrocarbon measurements showed reductions over the 6-yr. period. There were higher hydrocarbon mixing ratios and variability in the winter than summer, associated with less active photochemistry, lower oxidant mixing ratios resulting in longer chemical lifetimes, and lower boundary layer mixing heights in the winter.

Fig. 2 a, b, c The multi-year observed trend in the three toxic hydrocarbons studied

(BENZ = benzene; B124 = 1,2,4trimethylbenzene; BD13 = 1,3-butadiene). Reported as vertical bar statistics are the mean, median, 25th, 75th, max, min and a linear least-squares best fit line for each 3-month season

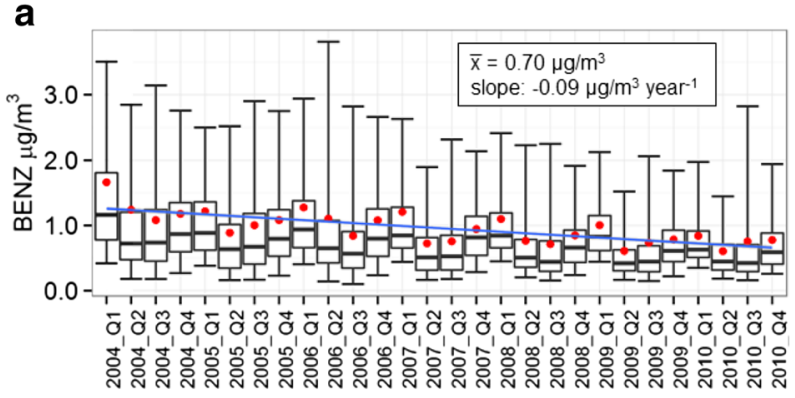

b

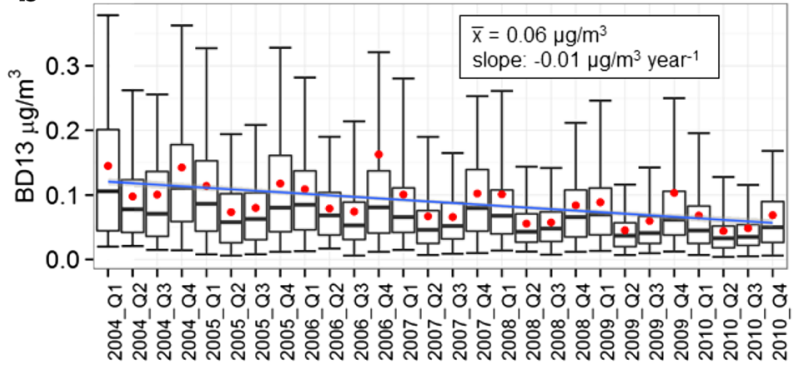

C

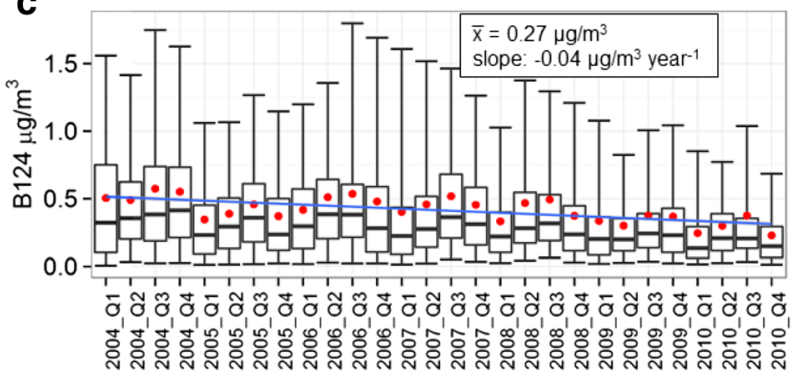


Fig. 3 a, b, c The multi-year observed trend in the three toxic hydrocarbons (BENZ = benzene; B124 = 1,2,4-trimethylbenzene; BD13 = 1,3-butadiene) plotted as yearly averages
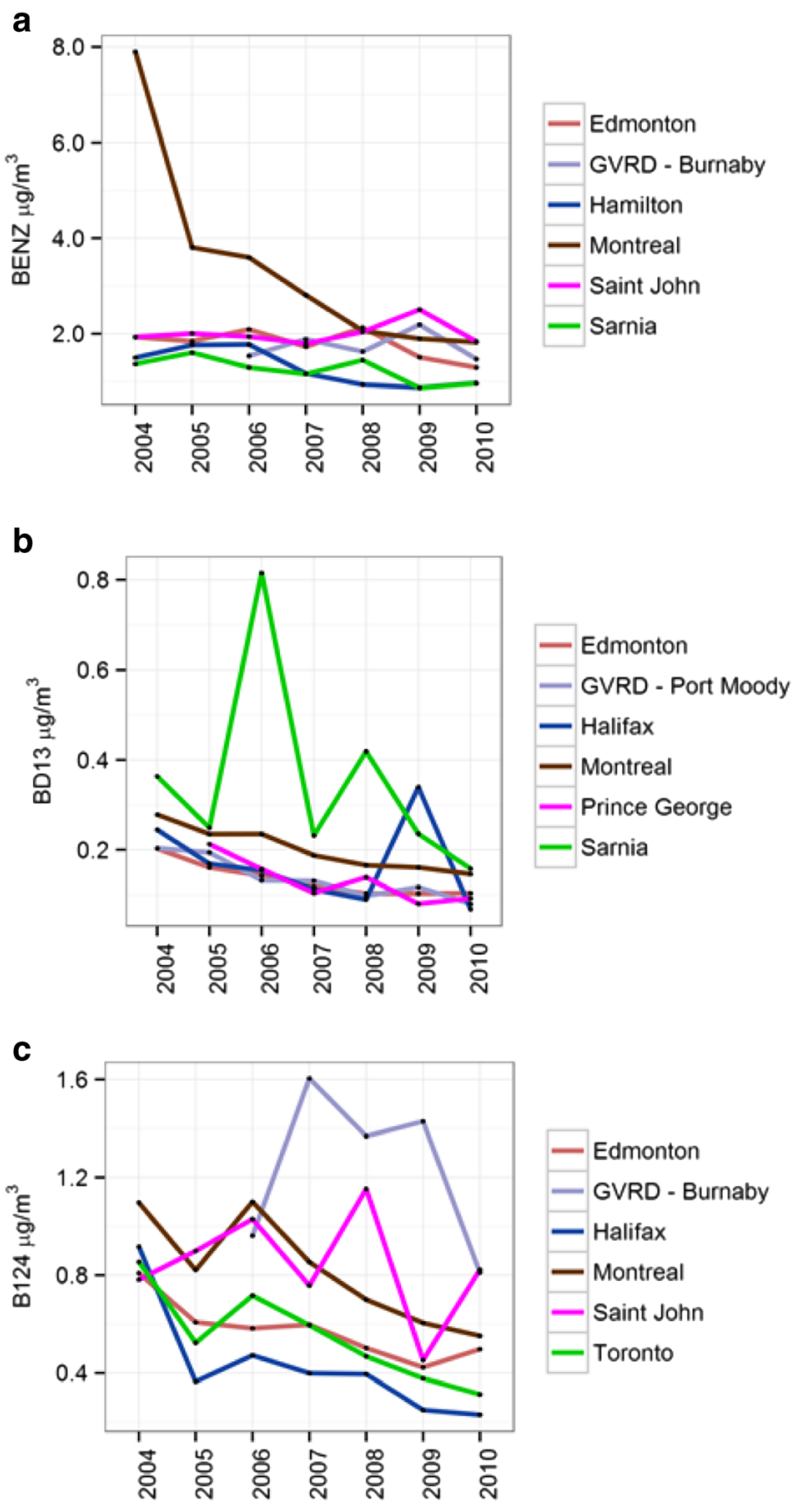

Benzene Figure 2a shows that benzene decreased by $13 \%$, on average, over the 6-yr. period. The declining trend was consistent from year to year. Fig. 3 a illustrates the trend in average yearly benzene for locations with the highest observed benzene. Montreal shows a marked improvement with benzene levels dropping from 8 to $2 \mu \mathrm{g} / \mathrm{m}^{3}$ over the 6-yr. period. Montreal is one of Canada's larger cities with a population of 1.6 million in 2010 and is on an island in the St. Lawrence River shared with industry (petrochemical refineries, solvent and paint production). Hamilton and Sarnia, both in southern Ontario, also showed a significant decrease. Hamilton is a mid-sized city and home to the steel industry and the metal smelter industry. Sarnia is a small town but is home of some of Canada's largest petrochemical 
refineries, as well as agricultural and chemical industries. The reader is referred to the 2010 Canada Smog Science Assessment for descriptions of the different regions and cities across Canada and the major emissions sources in each region (Section 7.3: Regional Air Pollutant Emissions and Areas of Concern).

1,3-butadiene Butadiene showed the largest decrease of all the species studied at $16 \%$ from 2004 to 2010 (Fig. 2b). The top 6 locations in terms of ambient concentration all showed a decrease. As Fig. 3b illustrates, Sarnia showed the greatest variability from year to year. Curren et al. (2006) presented a multi-year trend for data between 1995 and 2003 averaged across Canada. The slope calculated in Curren et al. (2006) was $-0.015 \mu \mathrm{g} / \mathrm{m}^{3} / \mathrm{yr}$. $(-0.0081 \mathrm{ppbv} / \mathrm{yr}$ ), for a linear fit from the data set using all the urban sites. This compares well with the slope $\left(-0.010 \mu \mathrm{g} / \mathrm{m}^{3} / \mathrm{yr}\right)$ calculated in Fig. $2 \mathrm{~b}$ from 2004 to 2010 . The increase in concentration for 2009 in Halifax is likely the result of a forest fire event that summer.

1,2,4-trimethylbenzene Overall, for all the NAPS sites, 1,2,4-trimethylbenzene dropped $15 \%$ from 2006 to 2010 (Fig. 2c). Most of the six sites showed a consistent decline, except for Burnaby Vancouver, British Columbia and Saint John, New Brunswick, which showed greater variability (Fig. 3c). Burnaby has several petrochemical refineries that have large emission factors for 1,2,4-trimethylbenzene. The Halifax location had a marked improvement, as concentration levels dropped from 0.9 to $0.2 \mu \mathrm{g} / \mathrm{m}^{3}$. Halifax is a mid-sized city on the east coast of Nova Scotia. Saint John is the largest city in New Brunswick. It is a coastal site with frequent marine inversions. The local emissions include a petrochemical refinery and ship/rail port activity.

Formaldehyde Figure 4a shows that formaldehyde declined marginally from 2004 to 2010 for the average of all the sites. Port Moody in Vancouver showed a steady increase while Winnipeg, Manitoba showed a steady decline (Fig. 5a). Winnipeg is a mid-sized city in central Canada. The other sites in Fig. 5a showed a lot of variability.

Acetaldehyde Figure $4 \mathrm{~b}$ illustrates that acetaldehyde did not show as large of a decline from 2006 to 2010, as the toxic hydrocarbons studied here. Montreal and Winnipeg showed a steady decline while the other sites showed a lot of variability from year to year (Fig. 5b). Unlike, the hydrocarbons, the seasonal cycle for formaldehyde and acetaldehyde showed an increase in mixing ratio in the summer due to increased biogenic emissions and photochemical secondary production.

Acrolein Figure 4c shows very little multi-year trend from the averages of all the NAPS sites. Winnipeg observed a steady decline and Port Moody, Vancouver an increase by a factor of 2.8, from 0.030 to $0.085 \mu \mathrm{g} / \mathrm{m}^{3}$ (Fig. 5c). Port Moody has a large shipping port accommodating trans-Pacific ship traffic which has shown an expansion over the multi-year period. Port Moody is also the fastest growing city by population in Metro Vancouver. Further discussion about the reliability of acrolein measurements are discussed in Section 3.2.1.

\subsection{Model evaluation}

For the model evaluation of toxic VOCs with surface measurements, the predictions from the 22.5-km grid spacing domains (west and east) were used. The impact of model grid spacing will be shown in section 3.3. 
Fig. 4 a, b, c The multi-year observed trend in the three toxic aldehydes studied $(\mathrm{HCHO}=$ formaldehyde; $\mathrm{CCHO}=$ acetaldehyde; ACRO $=$ acrolein). Reported as vertical bar statistics are the mean, median, 25th, 75th, max, min and a linear least-squares best fit line for each 3-month season

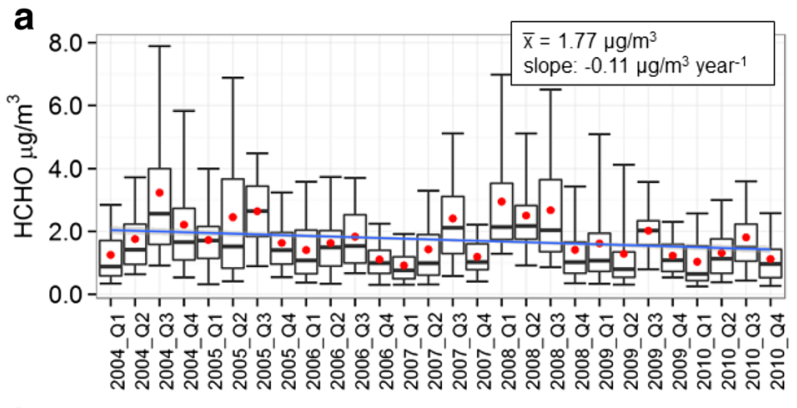

b

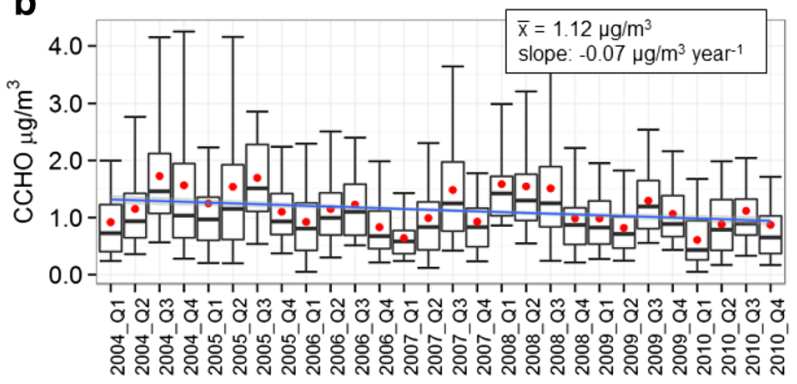

C

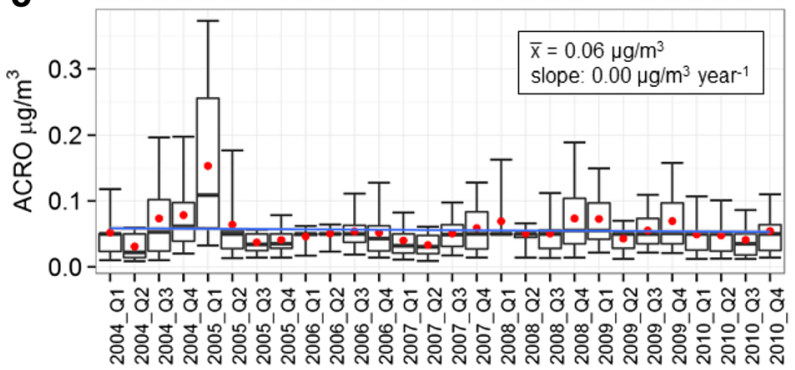

\subsubsection{Seasonal averages and spatial correlation for toxic VOCs}

The $22.5-\mathrm{km}$ grid spaced hourly model predictions were temporally averaged following the measurement sample time and paired with the NAPS measurements at the surface sites based on the location and time period of the observations. For each site, the model and measurement pairs were further averaged over 3-months (December to February, June to August) to create the winter and summer seasonal averages for 2006. Sites with less than 9 data points were not considered to have sufficient coverage to represent a seasonal average. Figs. 6 and 7 illustrate the results for the model plotted against the observations, where the points are the 3-month averages for each site. The blue points are wintertime averages and the red points are summertime averages. The symbols define the various site types (residential, agricultural, industrial, etc).

Benzene Figure 6a shows the model versus the observations for benzene with a linear least-squares best fit, $y=m x+b$. The correlation is fair with a calculated Pearson coefficient, $R$, of 0.53 and a slope of $\mathrm{m}=1.14 \pm 0.08$. The urban commercial sites with the highest observed benzene tend to be over-predicted. The observations with low benzene mixing ratios are 

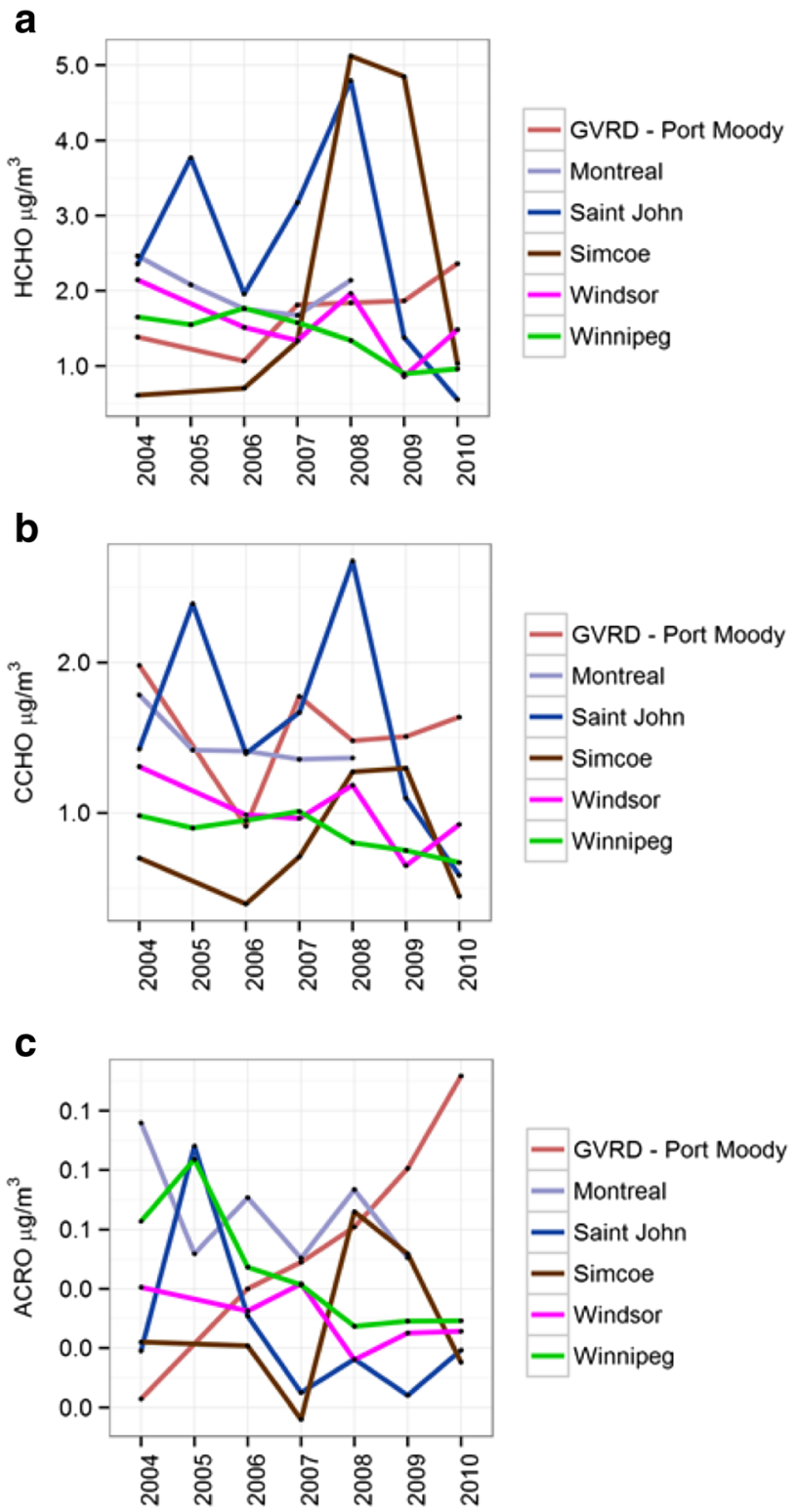

Fig. 5 a, b, c The multi-year observed trend in the three toxic hydrocarbons $(\mathrm{HCHO}=$ formaldehyde; $\mathrm{CCHO}=$ acetaldehyde; $\mathrm{ACRO}=$ acrolein) plotted as yearly averages

under-predicted, especially in the winter. This trend results in the predictions having a wider dynamic range than the observations. The observed summertime and wintertime average and standard deviation for benzene for all the points are $0.65 \pm 0.57 \mathrm{ppbv}$ and $1.05 \pm 0.53 \mathrm{ppbv}$, respectively. The modeled summertime and wintertime benzene are $0.91 \pm 0.76 \mathrm{ppbv}$ and $1.23 \pm 1.10 \mathrm{ppbv}$. The model is capable of predicting the seasonal increase in benzene from summer to winter (obs $\Delta=0.40 \mathrm{ppbv}$ vs. model $\Delta=0.32 \mathrm{ppbv}$ ). 
Fig. 6 a, b, c The correlations between modelled toxic hydrocarbon mixing ratio and observed values, where each point is a seasonal average for one site. The colour denotes the season and the symbol type denotes the site descriptor

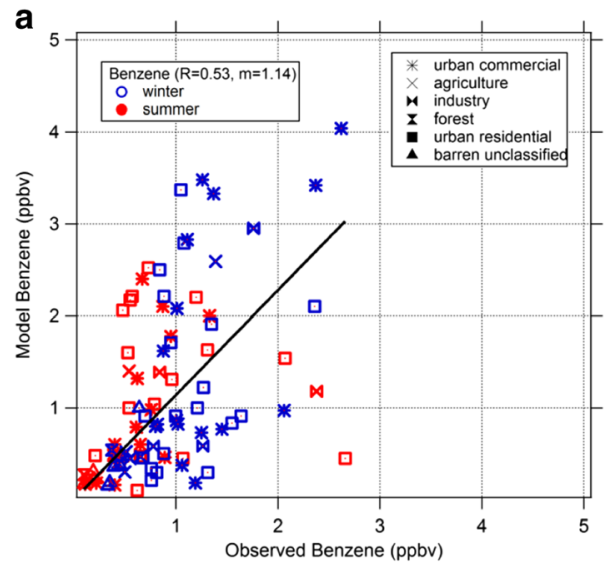

b

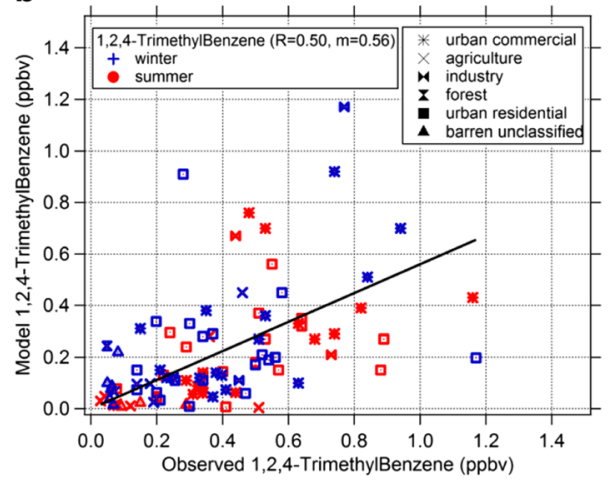

C

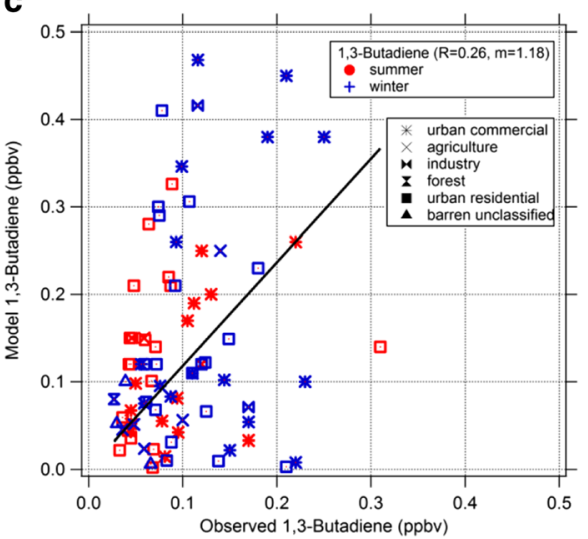

1,2,4-trimethylbenzene Figure $6 \mathrm{~b}$ shows that 1,2,4-trimethylbenzene tends to be under-predicted. The Pearson correlation coefficient is $\mathrm{R}=0.50$ and slope $\mathrm{m}=0.56 \pm 0.05$. The wintertime slope is slightly higher than the summertime slope showing that the under-prediction is worse in the summertime. The observed summertime and wintertime averages are $0.42 \pm 0.26$ and $0.36 \pm 0.25$, respectively. The modeled summertime and wintertime averages are $0.20 \pm 0.19$ and $0.25 \pm 0.29$. The observed 1,2,4-trimethylbenzene 
Fig. 7 a, b, c The correlations between modelled toxic aldehyde mixing ratio and observed values, where each point is a seasonal average for one site. The colour denotes the season and the symbol type denotes the site descriptor

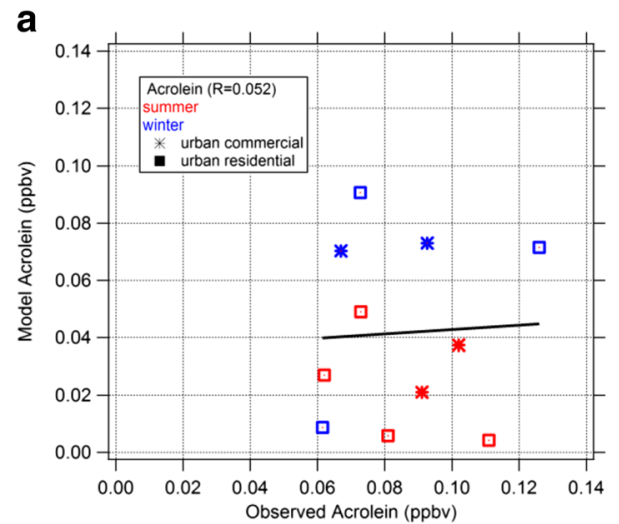

b
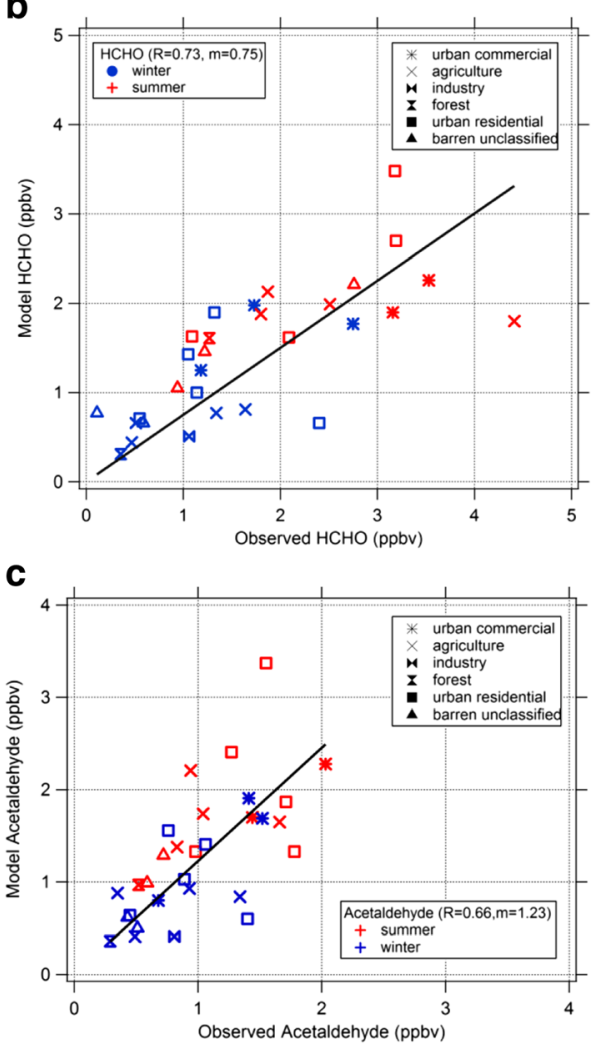

does not vary with season significantly, and this trend is also shown in the model results. There is further uncertainty in the VOC speciation profiles for alkyl benzenes because the profiles may not differentiate the isomers e.g. may only report total trimethylbenzenes.

1,3-butadiene Figure $6 \mathrm{c}$ shows that for butadiene the model has little prediction skill. The Pearson correlation coefficient is $\mathrm{R}=0.26$ and slope $\mathrm{m}=1.18 \pm 0.12$. The model intercept is large compared to the magnitude of the predictions. The model results have a wider dynamic range than observations. The highest modeled values are from wintertime. The observed 
summertime and wintertime averages are $0.083 \pm 0.056$ and $0.111 \pm 0.056 \mathrm{ppbv}$, respectively. The modelled summertime and wintertime averages are $0.12 \pm 0.08$ ppbv and $0.15 \pm 0.14$ ppbv. There is a small increase in 1,3-butadiene from summer to winter and the model does capture this seasonal change (obs $\Delta=0.03 \mathrm{ppbv}$, model $\Delta=0.03 \mathrm{ppbv}$ ).

Acrolein Figure 7a illustrates the correlation for acrolein. The model shows little predictive skill $(\mathrm{R}=0.052, \mathrm{~m}=0.076 \pm 0.49)$. The model predicts higher wintertime averages than summertime, but this trend is not captured in the observations. There may be several reasons for the poor agreement. There are a small number of points compared to the other toxic hydrocarbons because acrolein measurements use a different measurement technique with less frequent sampling. There are also fewer points above the detection limit because the ambient levels are relatively low compared to the concentrations on the blank cartridges. There may also be systematic negative and positive biases in the measurement technique due to an incomplete reaction of the acrolein with the DNPH reagent and due to ozone interference reactions on the cartridge absorbent forming acrolein. It is recommended that a systematic study of the measurement techniques for acrolein be performed, using the proton transfer reaction mass spectrometer (PTR-MS) as a reference. The newer PTR-MS technique does not pre-concentrate on an absorbent in sampling. The systematic negative bias in the summer may also be attributed to unaccounted for biomass burning emissions in the model (Akagi et al., 2011).

Formaldehyde Figure $7 \mathrm{~b}$ shows the correlation of model formaldehyde plotted against observations. The correlation is good with a Pearson coefficient $\mathrm{R}=0.73$ and slope $\mathrm{m}=0.750 \pm 0.05$. The summertime and wintertime average observed formaldehyde are $2.4 \pm 1.1 \mathrm{ppbv}$ and $1.14 \pm 0.73 \mathrm{ppbv}$. The summertime and wintertime modelled averages are $1.98 \pm 0.59 \mathrm{ppbv}$ and $0.98 \pm 0.53 \mathrm{ppbv}$, respectively. The summertime average is clearly higher than the wintertime average in both the model and observations. Generally, the higher modelled and observed averages were from the urban sites, but the rural sites had a high background mixing ratio in summer, likely associated with photochemical oxidation of biogenic emitted precursor VOCs like isoprene and monoterpenes.

OMI satellite data gave us the opportunity to evaluate the modelled formaldehyde column number densities. Figure $8 \mathrm{ab}$ shows the observed and modelled formaldehyde column densities for North America. The highest values were observed in the southeast US and California. The highest values in Canada were in several urban and industrial air sheds across the country including the Lower Fraser Valley, BC, northern Alberta, Windsor, ON and Montreal, QU. Figure S3 is the spatial correlation between the satellite observations versus coincident model data. The correlation is remarkably good with a Pearson coefficient $\mathrm{R}=0.90$, slope of 1.18 and small observed intercept. The model under-prediction, roughly $30 \%$ calculated from Figure S3, matches what was calculated from the NAPS observations very closely ( $25 \%$ under-prediction using the NAPS data and $30 \%$ under-prediction from OMI data).

Acetaldehyde Figure 7c illustrates that the model has good predictive skill for acetaldehyde. The correlation statistics are $\mathrm{R}=0.66$ and slope $\mathrm{m}=1.23 \pm 0.09$ and the model intercept is near zero. Again, the summertime data are higher than the wintertime data, but not to the same degree as formaldehyde. The highest data are from the urban residential and urban commercial sites. The agricultural sites have data generally higher than the forest and barren sites. The summertime and wintertime observed average acetaldehyde are $1.22 \pm 0.48 \mathrm{ppbv}$ and 
a

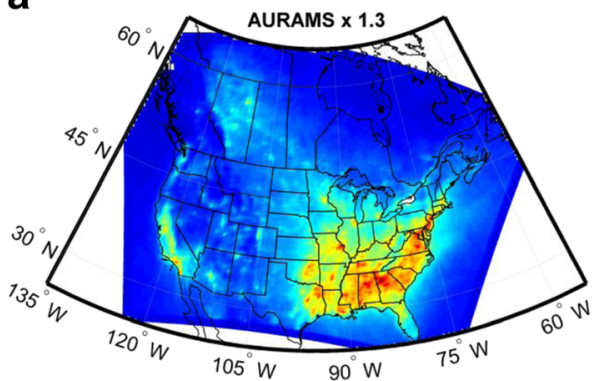

b

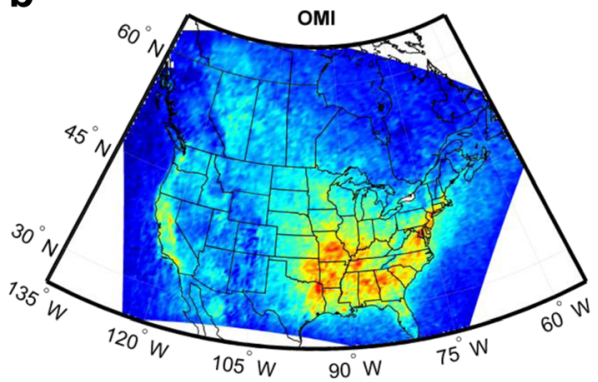

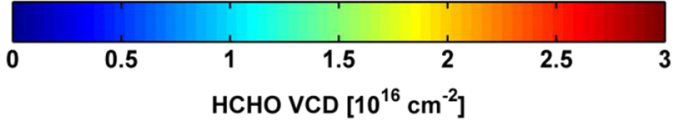

Fig. 8 a, b The averaged OMI satellite-derived formaldehyde column number density map for summertime conditions (June- August 2006) compared to the coincident AURAMS-derived column number density

$0.83 \pm 0.41 \mathrm{ppbv}$. The summertime and wintertime modeled averages are $1.75 \pm 0.65 \mathrm{ppbv}$ and $0.91 \pm 0.49 \mathrm{ppbv}$, respectively. Thus, the summertime period tends to contribute more to the over-prediction than the wintertime.

\subsubsection{Model evaluation for other pollutants: ozone, nitrogen dioxide, and carbon monoxide}

The routine hourly ozone and nitrogen dioxide surface observations collected by Environment Canada NAPS and the US AIRNOW networks provide a validation of the model predictions for other important pollutants, which affect the oxidant capacity for the troposphere. In turn, the oxidizing capacity of the troposphere affects the gas-phase chemical lifetime of the toxic VOCs. The wintertime $2006 \mathrm{O}_{3}$ mean bias was -0.58 ppbv with a Pearson correlation coefficient, $\mathrm{R}=0.53$ for the hourly data from all the sites in Canada and the US. The summertime $\mathrm{O}_{3}$ mean bias was +5.1 ppbv with a correlation coefficient, $\mathrm{R}=0.66$. Eastern North America showed better statistical scores than western North America for both summer and winter. These $\mathrm{O}_{3}$ scores are typical of what is expected with similar peer-reviewed regional air quality models (e.g. WRF-CHEM in Makar et al. 2014b and CMAQ in Makar et al. 2014c).

The hourly $\mathrm{NO}_{2}$ data from NAPS and AIRNOW can also be used to validate AURAMS. For the wintertime and summertime, the $\mathrm{NO}_{2}$ correlation has $\mathrm{R}=0.47$ and $\mathrm{R}=0.43$, respectively, for 2006 . The model mean bias was $-2.4 \mathrm{ppbv}$ and $-4.9 \mathrm{ppbv}$ for the summertime and wintertime. These $\mathrm{NO}_{2}$ scores for the surface sites are also reasonable compared to peer-models. The OMI satellite provides a new opportunity to evaluate AURAMS for the predicted $\mathrm{NO}_{2}$ column densities, at a similar gridded spatial resolution. Figure 9ab presents the OMI satellite $\mathrm{NO}_{2}$ 3-month summertime-average column density for 2006 over North America along with the AURAMS predicted column density. The two are in very good agreement, a conclusion substantiated by Figure S4 which shows the corresponding correlation plot as observation versus model. The Pearson coefficient is excellent, $\mathrm{R}=0.91$, slope $=0.88$ and near zero intercept.

The total VOC OH-reactivity predictions from AURAMS have also been evaluated previously (Stroud et al. 2008) and shown to yield reasonable predictions for total $\mathrm{OH}$ 
a

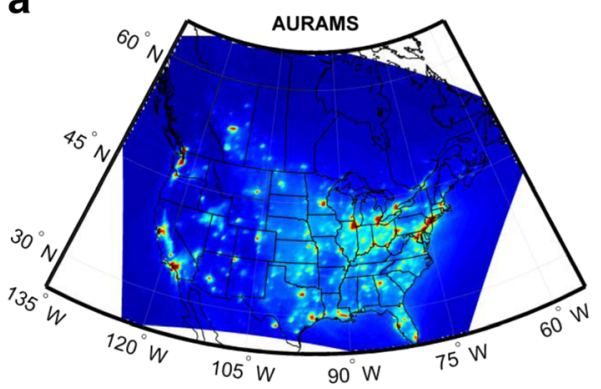

b

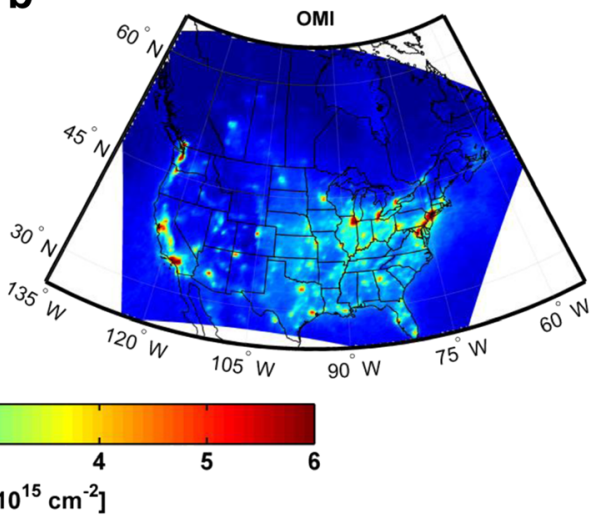

Fig. 9 a, b The averaged OMI satellite-derived $\mathrm{NO}_{2}$ column number density map for summertime conditions (June- August 2006) compared to the coincident AURAMS-derived column number density

reactivity, given the uncertainties. Here, the modelled $\mathrm{CO}$ was evaluated against the MOPITT CO column number densities (Fig. 10a, b). The agreement was excellent with a slope of 0.99 and negative observed intercept of $1.15 \times 10^{17}$ molecules $/ \mathrm{cm}^{2}$ (see Figure S5). This can be compared to an approximate background number density for eastern North America of $2 \times 10^{18}$ molecules $/ \mathrm{cm}^{2}$. Compared to this background, the observed intercept is small. The correlation was also good with a Pearson coefficient, $\mathrm{R}=0.74$.

Overall, the $\mathrm{O}_{3}, \mathrm{NO}_{2}, \mathrm{CO}$ and prior results for total VOC suggest that the precursor emissions (NO, CO, VOCs) determining the oxidizing capacity of the troposphere $\left(\mathrm{O}_{3}, \mathrm{OH}\right.$, $\mathrm{NO}_{3}$ ) are modelled in AURAMS reasonably well (see Makar et al. 2014c for a comparison of AURAMS and CMAQ results).

\subsubsection{Temporal correlations for toxic VOCs}

Here, we evaluate the temporal trends in the daily surface data for air toxics for several rural sites near large cities. The focus was on whether the modelling system could predict the synoptic scale
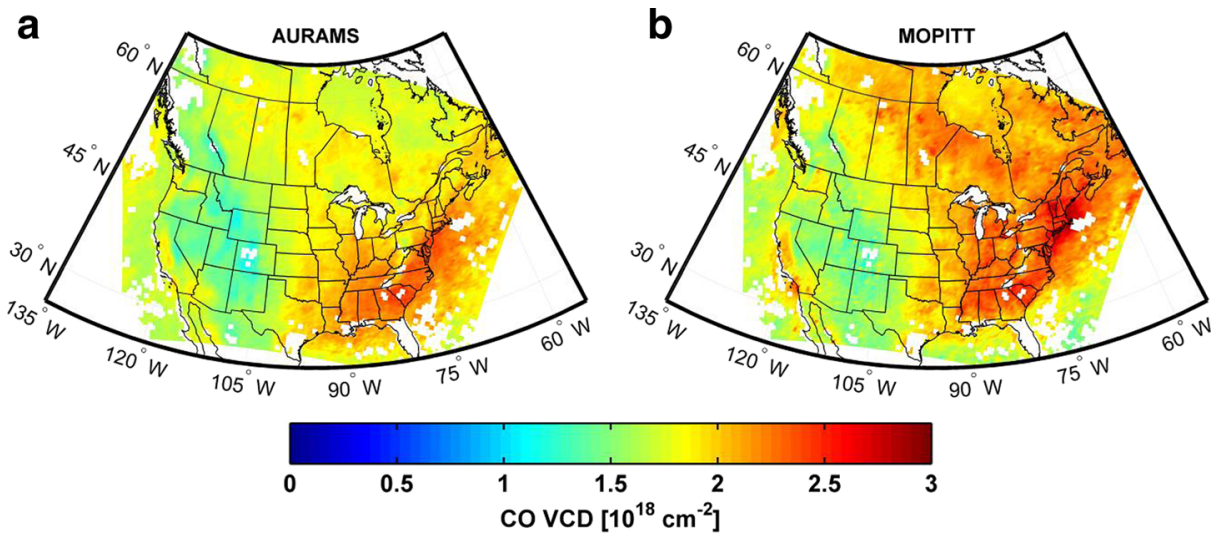

Fig. 10 a, b The averaged MOPPIT satellite-derived CO column number density map for summertime conditions (June- August 2006) compared to the coincident AURAMS-derived column number density 
wind systems that affect the transport of pollutants from source regions to rural areas. For this analysis, 4 sites were chosen across Canada, namely, Keji National Park in Nova Scotia, Egbert in Ontario, Elk Island in Alberta and Hope in British Columbia. At these sites, samples were collected for $4 \mathrm{~h}$ in the afternoon on every third day. To ensure that the temporal correlation between the model and observations was being evaluated, we focus on only the summertime data so that we do not simply correlate differences in season. Figure 11 is the correlation between model and measurements for benzene. The colour code differentiates the four sites. The correlations are fair to excellent for all four locations $(\mathrm{R}=0.43$ to 0.96$)$ suggesting the model is capturing the regional scale transport of benzene from the source regions to the rural sites.

\subsubsection{Weekend and weekday variations for toxic VOCs}

The sampling strategy also enabled a study of how the model performed at capturing the differences between the toxic VOCs on average for weekend compared to weekdays. First, we studied the changes for a short-lived toxic species with large urban sources, 1,2,4-trimethylbenzene, for two of Canada's largest cities, Toronto and Montreal. For this analysis, we used both the summer and winter data to increase the sampling size. The average weekday observed and modelled mixing ratios are 0.98 and $0.42 \mathrm{ppbv}$, respectively. This can be compared to the average weekend observed and modelled mixing ratios 0.68 and $0.27 \mathrm{ppbv}$. The increase in the average of weekdays compared to weekends is 1.44 from the observations. Despite negative biases in model predictions, the model performed well at capturing the weekday enhancement compared to weekend average, predicting a weekday to weekend ratio of 1.55.

Second, a weekday and weekend analysis was also performed for a longer lived species, benzene, which has a large source from the oil and gas sector, for two of Canada's largest cities

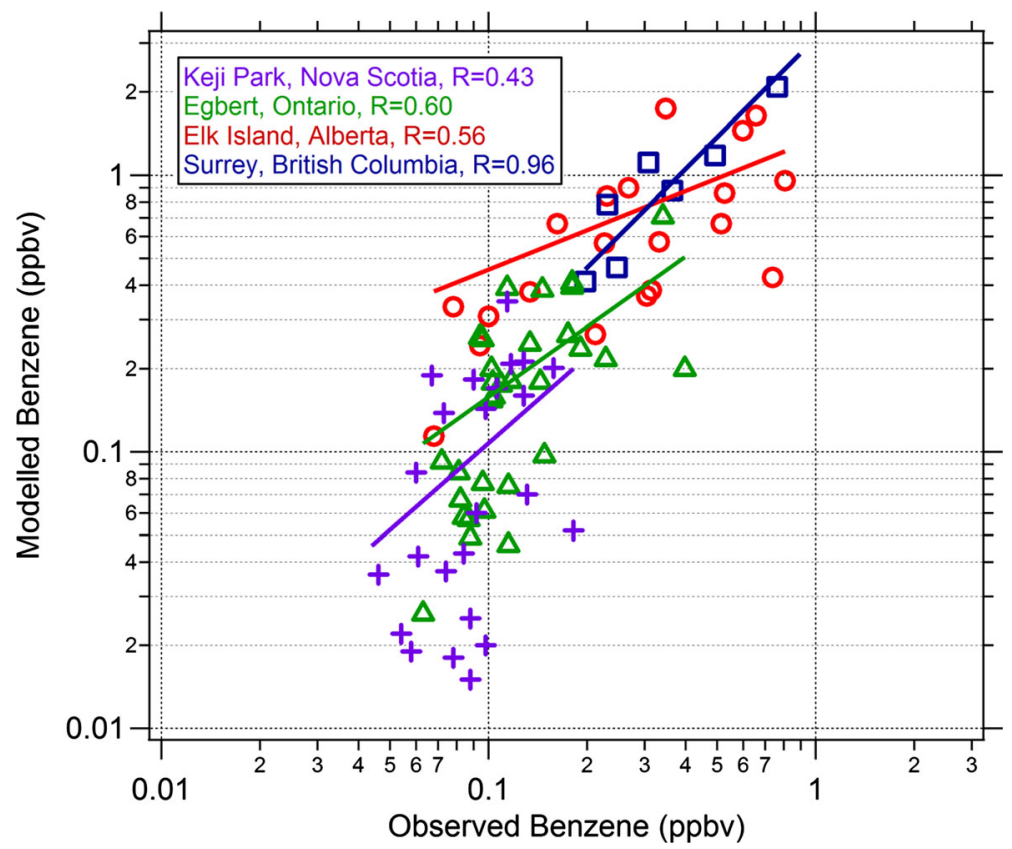

Fig. 11 The correlation between model and measurements for benzene, using hourly summertime data, for 4 rural locations 
in the oil and gas region of Alberta, Edmonton and Calgary. The average weekday observed and modelled mixing ratios are 1.09 and $2.68 \mathrm{ppbv}$, while the average weekend observed and modelled mixing ratios were 0.79 and $2.97 \mathrm{ppbv}$. The observations show, on average, that weekday mixing ratios in the urban areas of Alberta are higher than weekends. Conversely, the model does not show an increase on the weekday average. It might be expected that if the benzene emissions were from the industrial sector, which ran independent of the day of week, then there might not be as strong a weekday/weekend effect. However, the benzene observations show that emissions are higher on weekdays compared to weekends suggesting that urban source day of week variations also play a role in affecting the toxic VOC levels at Edmonton and Calgary.

\subsection{Impact of model grid spacing}

The model was run for the continental domain at 45-km grid spacing and for two nested regional domains covering east and west Canada at $22.5-\mathrm{km}$ grid spacing. This gives an opportunity to evaluate the impact on the change in model grid spacing on predictions for the toxic VOCs (Figures 12ab, 13ab and 14ab).

For benzene, in western Canada, the winter predictions showed a significantly smaller bias with the $22.5-\mathrm{km}$ regional grid spacing compared to $45-\mathrm{km}$ continental grid spacing. The summer benzene predictions in western Canada, on average, went from under-predictions to over-predictions. In eastern Canada, there was less change in predictive skill with the higher grid resolution.

For the reactive hydrocarbons (1,2,4-trimethylbenzene and 1,3-butadiene), the higher model grid resolution resulted in a larger average predicted mixing ratio and more variability, given by the spread in 95th and 5th percentiles. For 1,3-butadiene, in the west, the model performance for the median was significantly improved at higher grid resolution, while the mean went from an under-prediction to a slight over-prediction. In the east, the modeled butadiene went to a larger over-prediction at the lower grid spacing. For 1,2,4-trimethylbenzene, in the west and east, the model showed a significant improvement at the high grid resolution.

For acrolein, in the west, there was little change in model skill at the higher grid resolution. In the east, there was an improvement in model bias at higher resolution, but there still remained a negative bias in both seasons.

For formaldehyde and acetaldehyde, there were small improvements in model performance in both seasons with an increase in model grid resolution.

In general, the model performance was either similar or better with the higher grid resolution. For this reason, we used the higher resolution model predictions in our evaluation discussed already (section 3.2) and, next, for source apportionment (section 3.4).

\subsection{Emission source apportionment for toxic VOCs}

Of particular interest, is the role that mobile emissions play in affecting the mixing ratio of the studied toxic VOCs. This is because mobile emissions have and continue to undergo regulations. To address this topic, we added additional tracer chemical species to the model which were then transported and chemically removed in AURAMS like the normal toxic species, except that their only source was from either mobile (on-road + off-road) emissions (e.g. MBENZ) or "area + point" emissions (e.g. PBENZ). Biogenic emissions and shipping 
Fig. 12 a, b Comparison of measurement with model (panel a is benzene, panel $\mathrm{b}$ is $1,2,4-$ trimethylbenzene) showing the impact of model grid spacing on statistical measures (mean, median, 25th and 75th percentiles, 5th and 95 th percentiles) a

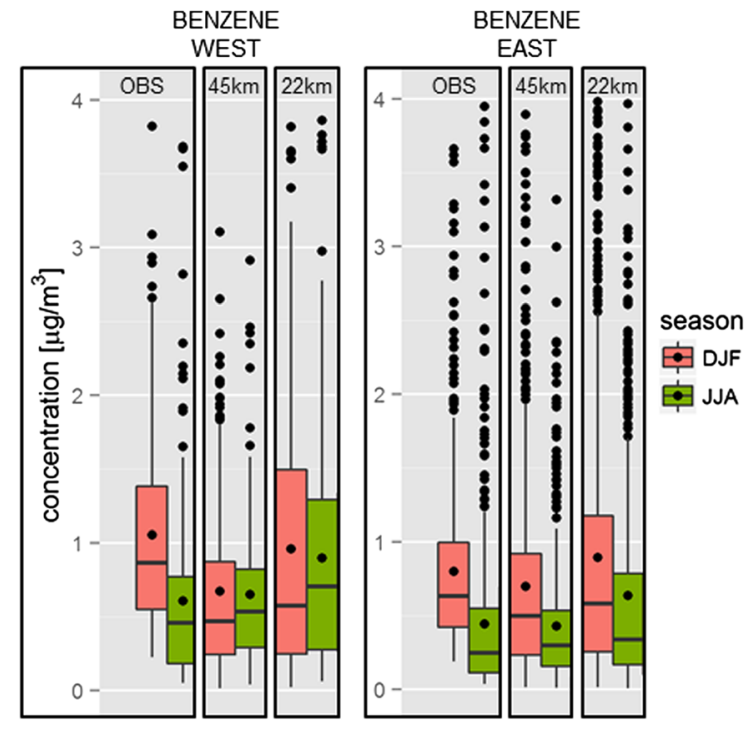

b

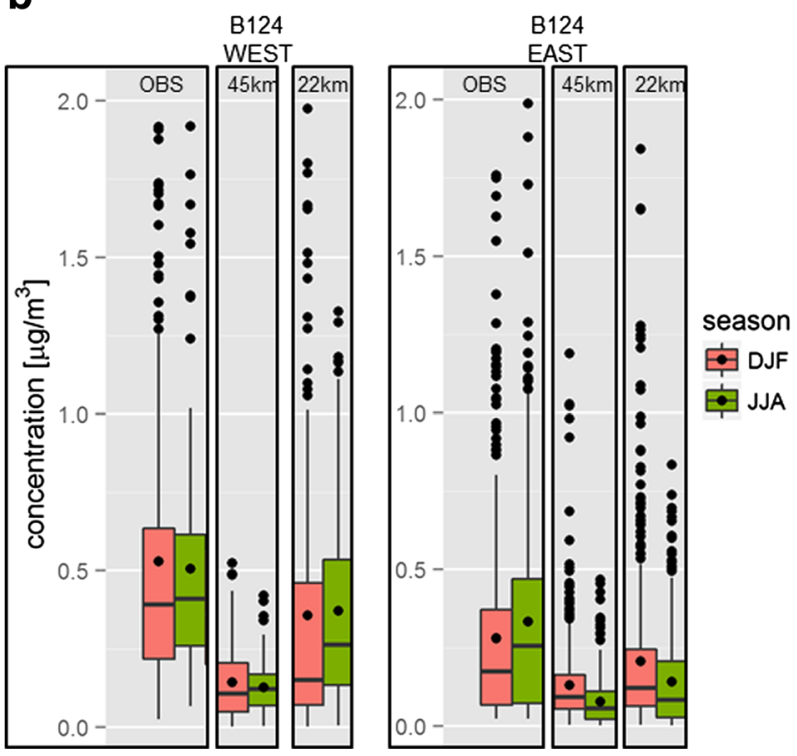

emissions are summed into the "area + point" emission fields. Residential sources, such as home heating and food cooking, are also summed into the "area + point" emissions. Secondary production of toxics is defined as chemical production from gas-phase precursors.

Despite the chemical removal, the additional tracer compounds were not however allowed to affect the oxidant concentration $\left(\mathrm{OH}, \mathrm{O}_{3}, \mathrm{NO}_{3}\right)$, as the latter is already impacted by the existing net toxic species (for example, BENZ). The ratio of the mobile tracer to the normal species (e.g. MBENZ/BENZ) then yields the contribution of the mobile emissions to the toxic 
Fig. 13 a, b Comparison of measurement with model (panel a is 1,3-butadiene, panel $\mathrm{b}$ is acrolein) showing the impact of model grid spacing on statistical measures (mean, median, 25th and 75 th percentiles, 5 th and 95 th percentiles) a
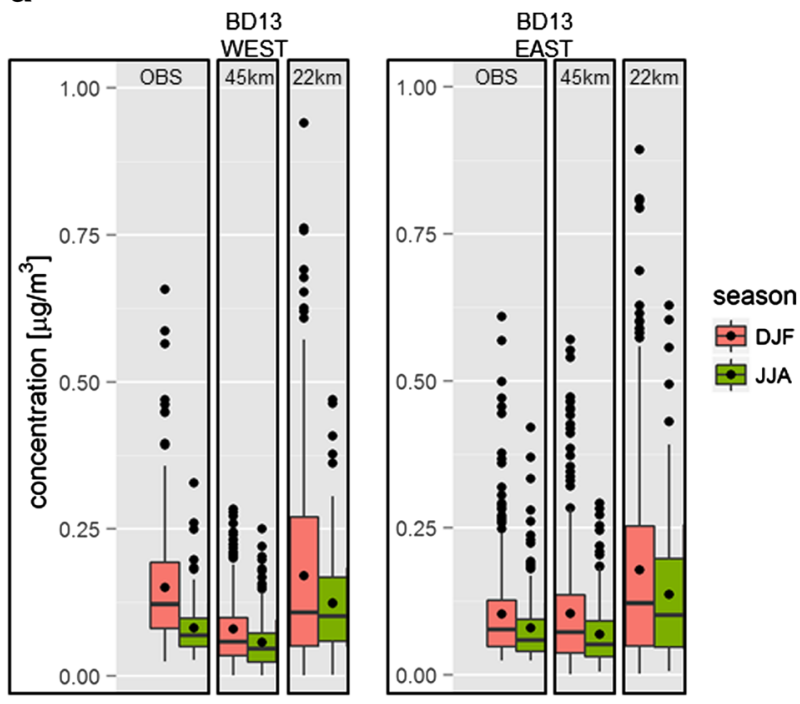

b

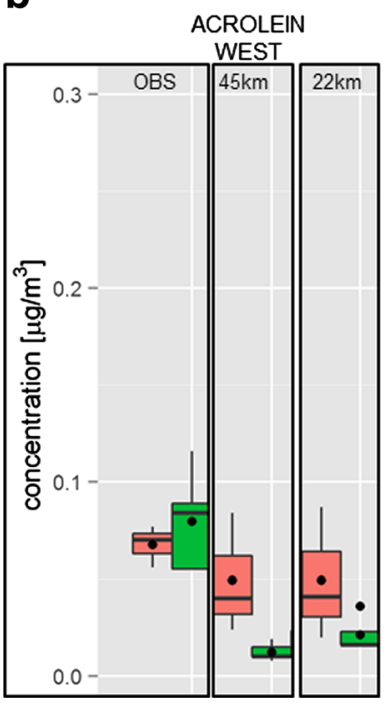

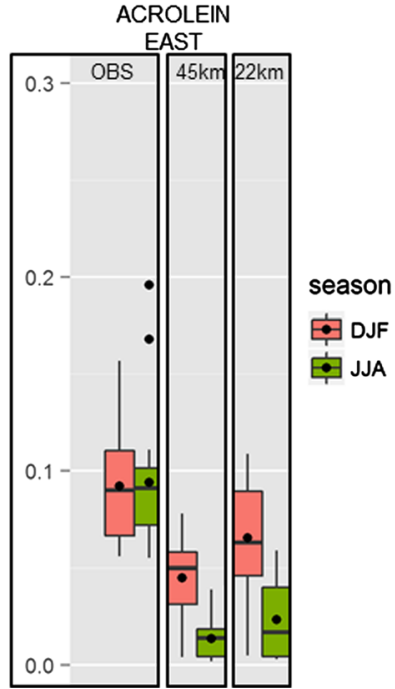

VOC species at any given point and time in the model output. Table 1 lists the results for the major cities across Canada and for background sites outside these cities.

It should be noted that the source apportionment results are only as good as the emission inventory available. The model evaluation, shown above, should be considered when deriving conclusions from the model. Given that the model performs poorly for acrolein predictions suggests the source apportionment for this species has a large uncertainty. Future work should focus on improving model performance for acrolein. A two prong approach is recommended with focus on both improving model emissions and improving measurement techniques for acrolein. In tabulating the source apportionment results, we have ordered the species, by 
Fig. 14 a, b Comparison of measurement with model (panel a is formaldeyde, panel $b$ is acetaldehyde) showing the impact of model grid spacing on statistical measures (mean, median, 25th and 75 th percentiles, 5 th and 95 th percentiles)
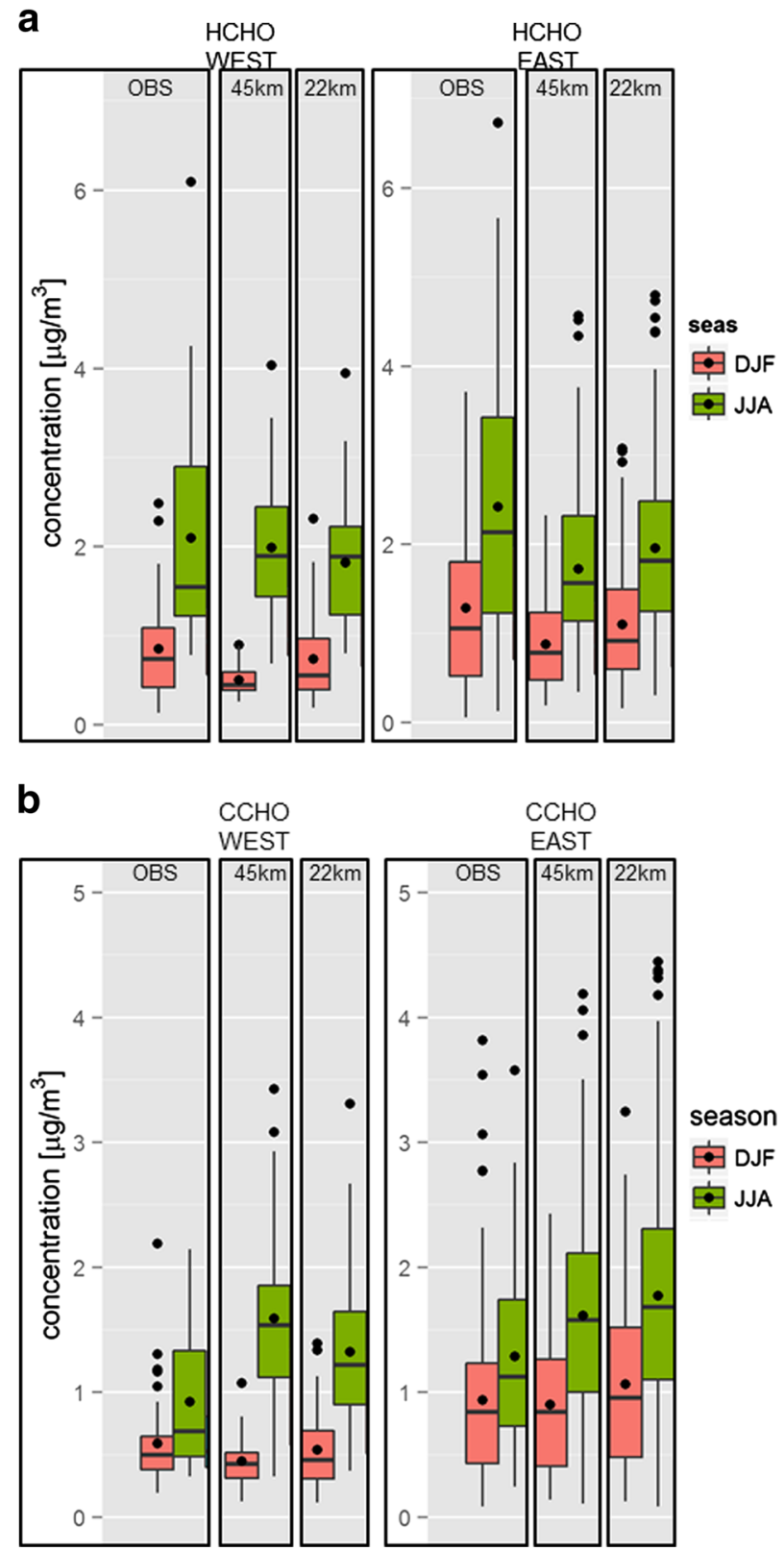

column, in terms of the magnitude of their correlation coefficient, previously presented in Section 3.2.1.

\subsubsection{Vancouver and hope, British Columbia}

In the wintertime, the primary mobile emissions contribute approximately $30 \%$ to the aliphatic aldehydes (formaldehyde, acetaldehyde) at both Vancouver and Hope, whereas the area/point 
Table 1 Source contributions for major cities and rural sites across Canada separated by season

\begin{tabular}{|c|c|c|c|c|c|c|c|}
\hline & $\begin{array}{l}\text { Fractional } \\
\text { Proportion }\end{array}$ & $\begin{array}{l}\mathrm{HCHO} \\
\mathrm{R}=0.73\end{array}$ & $\begin{array}{l}\mathrm{CCHO} \\
\mathrm{R}=0.66\end{array}$ & $\begin{array}{l}\text { BENZ } \\
\mathrm{R}=0.53\end{array}$ & $\begin{array}{l}\mathrm{B} 124 \\
\mathrm{R}=0.50\end{array}$ & $\begin{array}{l}\mathrm{BD} 13 \\
\mathrm{R}=0.26\end{array}$ & $\begin{array}{l}\text { ACRL } \\
\mathrm{R}=0.052\end{array}$ \\
\hline \multicolumn{8}{|c|}{ Eastern Canada } \\
\hline $\begin{array}{l}\text { Toronto } \\
\text { Winter }\end{array}$ & $\begin{array}{l}\text { Secondary } \\
\text { Mobile } \\
\text { Area + Point }\end{array}$ & $\begin{array}{l}0.34 \\
0.21 \\
0.45\end{array}$ & $\begin{array}{l}0.41 \\
0.16 \\
0.43\end{array}$ & $\begin{array}{l}0 \\
0.45 \\
0.55\end{array}$ & $\begin{array}{l}0 \\
0.62 \\
0.38\end{array}$ & $\begin{array}{l}0 \\
0.57 \\
0.43\end{array}$ & $\begin{array}{l}0.19 \\
0.34 \\
0.47\end{array}$ \\
\hline $\begin{array}{l}\text { Egbert } \\
\text { Winter }\end{array}$ & $\begin{array}{l}\text { Secondary } \\
\text { Mobile } \\
\text { Area + Point }\end{array}$ & $\begin{array}{l}0.67 \\
0.14 \\
0.19\end{array}$ & $\begin{array}{l}0.62 \\
0.15 \\
0.23\end{array}$ & $\begin{array}{l}0 \\
0.50 \\
0.50\end{array}$ & $\begin{array}{l}0 \\
0.73 \\
0.27\end{array}$ & $\begin{array}{l}0 \\
0.46 \\
0.54\end{array}$ & $\begin{array}{l}0.30 \\
0.16 \\
0.54\end{array}$ \\
\hline $\begin{array}{l}\text { Montreal } \\
\text { Winter }\end{array}$ & $\begin{array}{l}\text { Secondary } \\
\text { Mobile } \\
\text { Area + Point }\end{array}$ & $\begin{array}{l}0.13 \\
0.25 \\
0.62\end{array}$ & $\begin{array}{l}0.37 \\
0.14 \\
0.50\end{array}$ & $\begin{array}{l}0 \\
0.46 \\
0.54\end{array}$ & $\begin{array}{l}0 \\
0.48 \\
0.52\end{array}$ & $\begin{array}{l}0 \\
0.88 \\
0.12\end{array}$ & $\begin{array}{l}0.13 \\
0.22 \\
0.65\end{array}$ \\
\hline $\begin{array}{l}\text { St. Anicet } \\
\text { Winter }\end{array}$ & $\begin{array}{l}\text { Secondary } \\
\text { Mobile } \\
\text { Area + Point }\end{array}$ & $\begin{array}{l}0.57 \\
0.12 \\
0.31\end{array}$ & $\begin{array}{l}0.53 \\
0.14 \\
0.33\end{array}$ & $\begin{array}{l}0 \\
0.51 \\
0.49\end{array}$ & $\begin{array}{l}0 \\
0.75 \\
0.25\end{array}$ & $\begin{array}{l}0 \\
0.66 \\
0.34\end{array}$ & $\begin{array}{l}0.24 \\
0.10 \\
0.66\end{array}$ \\
\hline $\begin{array}{l}\text { Toronto } \\
\text { Summer }\end{array}$ & $\begin{array}{l}\text { Secondary } \\
\text { Mobile } \\
\text { Area + Point }\end{array}$ & $\begin{array}{l}0.71 \\
0.12 \\
0.17\end{array}$ & $\begin{array}{l}0.84 \\
0.063 \\
0.093\end{array}$ & $\begin{array}{l}0 \\
0.42 \\
0.58\end{array}$ & $\begin{array}{l}0 \\
0.64 \\
0.36\end{array}$ & $\begin{array}{l}0 \\
0.61 \\
0.39\end{array}$ & $\begin{array}{l}0.48 \\
0.35 \\
0.17\end{array}$ \\
\hline $\begin{array}{l}\text { Egbert } \\
\text { Summer }\end{array}$ & $\begin{array}{l}\text { Secondary } \\
\text { Mobile } \\
\text { Area + Point }\end{array}$ & $\begin{array}{l}0.95 \\
0.023 \\
0.023\end{array}$ & $\begin{array}{l}0.97 \\
0.013 \\
0.015\end{array}$ & $\begin{array}{l}0 \\
0.50 \\
0.50\end{array}$ & $\begin{array}{l}0 \\
0.80 \\
0.20\end{array}$ & $\begin{array}{l}0 \\
0.53 \\
0.47\end{array}$ & $\begin{array}{l}0.38 \\
0.14 \\
0.48\end{array}$ \\
\hline $\begin{array}{l}\text { Montreal } \\
\text { Summer }\end{array}$ & $\begin{array}{l}\text { Secondary } \\
\text { Mobile } \\
\text { Area + Point }\end{array}$ & $\begin{array}{l}0.69 \\
0.052 \\
0.26\end{array}$ & $\begin{array}{l}0.92 \\
0.037 \\
0.044\end{array}$ & $\begin{array}{l}0 \\
0.40 \\
0.60\end{array}$ & $\begin{array}{l}0 \\
0.50 \\
0.50\end{array}$ & $\begin{array}{l}0 \\
0.93 \\
0.07\end{array}$ & $\begin{array}{l}0.39 \\
0.26 \\
0.35\end{array}$ \\
\hline $\begin{array}{l}\text { St. Anicet } \\
\text { Summer }\end{array}$ & $\begin{array}{l}\text { Secondary } \\
\text { Mobile } \\
\text { Area + Point }\end{array}$ & $\begin{array}{l}0.96 \\
0.022 \\
0.021\end{array}$ & $\begin{array}{l}0.97 \\
0.013 \\
0.014\end{array}$ & $\begin{array}{l}0 \\
0.59 \\
0.41\end{array}$ & $\begin{array}{l}0 \\
0.90 \\
0.10\end{array}$ & $\begin{array}{l}0 \\
0.85 \\
0.15\end{array}$ & $\begin{array}{l}0.37 \\
0.12 \\
0.51\end{array}$ \\
\hline \multicolumn{8}{|c|}{ Western Canada } \\
\hline $\begin{array}{l}\text { Vancouver } \\
\text { Winter }\end{array}$ & $\begin{array}{l}\text { Secondary } \\
\text { Mobile } \\
\text { Area + Point }\end{array}$ & $\begin{array}{l}0.21 \\
0.32 \\
0.47\end{array}$ & $\begin{array}{l}0.19 \\
0.28 \\
0.53\end{array}$ & $\begin{array}{l}0 \\
0.45 \\
0.55\end{array}$ & $\begin{array}{l}0 \\
0.64 \\
0.36\end{array}$ & $\begin{array}{l}0 \\
0.56 \\
0.44\end{array}$ & $\begin{array}{l}0.09 \\
0.19 \\
0.72\end{array}$ \\
\hline $\begin{array}{l}\text { Hope } \\
\text { Winter }\end{array}$ & $\begin{array}{l}\text { Secondary } \\
\text { Mobile } \\
\text { Area + Point }\end{array}$ & $\begin{array}{l}0.093 \\
0.31 \\
0.59\end{array}$ & $\begin{array}{l}0.24 \\
0.34 \\
0.43\end{array}$ & $\begin{array}{l}0 \\
0.46 \\
0.54\end{array}$ & $\begin{array}{l}0 \\
0.48 \\
0.52\end{array}$ & $\begin{array}{l}0 \\
0.88 \\
0.12\end{array}$ & $\begin{array}{l}0.30 \\
0.14 \\
0.56\end{array}$ \\
\hline $\begin{array}{l}\text { Edmonton } \\
\text { Winter }\end{array}$ & $\begin{array}{l}\text { Secondary } \\
\text { Mobile } \\
\text { Area + Point }\end{array}$ & $\begin{array}{l}0.15 \\
0.56 \\
0.29\end{array}$ & $\begin{array}{l}0.26 \\
0.44 \\
0.30\end{array}$ & $\begin{array}{l}0 \\
0.54 \\
0.46\end{array}$ & $\begin{array}{l}0 \\
0.047 \\
0.95\end{array}$ & $\begin{array}{l}0 \\
0.73 \\
0.26\end{array}$ & $\begin{array}{l}0.06 \\
0.22 \\
0.72\end{array}$ \\
\hline $\begin{array}{l}\text { Elk Island } \\
\text { Winter }\end{array}$ & $\begin{array}{l}\text { Secondary } \\
\text { Mobile } \\
\text { Area + Point }\end{array}$ & $\begin{array}{l}0.34 \\
0.37 \\
0.29\end{array}$ & $\begin{array}{l}0.40 \\
0.29 \\
0.31\end{array}$ & $\begin{array}{l}0 \\
0.29 \\
0.71\end{array}$ & $\begin{array}{l}0 \\
0.37 \\
0.63\end{array}$ & $\begin{array}{l}0 \\
0.45 \\
0.55\end{array}$ & $\begin{array}{l}0.050 \\
0.090 \\
0.86\end{array}$ \\
\hline $\begin{array}{l}\text { Vancouver } \\
\text { Summer }\end{array}$ & $\begin{array}{l}\text { Secondary } \\
\text { Mobile } \\
\text { Area + Point }\end{array}$ & $\begin{array}{l}0.73 \\
0.14 \\
0.13\end{array}$ & $\begin{array}{l}0.84 \\
0.096 \\
0.063\end{array}$ & $\begin{array}{l}0 \\
0.42 \\
0.58\end{array}$ & $\begin{array}{l}0 \\
0.66 \\
0.34\end{array}$ & $\begin{array}{l}0 \\
0.61 \\
0.39\end{array}$ & $\begin{array}{l}0.34 \\
0.17 \\
0.59\end{array}$ \\
\hline $\begin{array}{l}\text { Hope } \\
\text { Summer }\end{array}$ & $\begin{array}{l}\text { Secondary } \\
\text { Mobile } \\
\text { Area + Point }\end{array}$ & $\begin{array}{l}0.95 \\
0.0077 \\
0.042\end{array}$ & $\begin{array}{l}0.99 \\
0.0093 \\
0.0045\end{array}$ & $\begin{array}{l}0 \\
0.40 \\
0.60\end{array}$ & $\begin{array}{l}0 \\
0.50 \\
0.50\end{array}$ & $\begin{array}{l}0 \\
0.93 \\
0.07\end{array}$ & $\begin{array}{l}0.48 \\
0.13 \\
0.39\end{array}$ \\
\hline $\begin{array}{l}\text { Edmonton } \\
\text { Summer }\end{array}$ & $\begin{array}{l}\text { Secondary } \\
\text { Mobile } \\
\text { Area + Point }\end{array}$ & $\begin{array}{l}0.72 \\
0.19 \\
0.086\end{array}$ & $\begin{array}{l}0.84 \\
0.10 \\
0.061\end{array}$ & $\begin{array}{l}0 \\
0.50 \\
0.50\end{array}$ & $\begin{array}{l}0 \\
0.057 \\
0.94\end{array}$ & $\begin{array}{l}0 \\
0.76 \\
0.24\end{array}$ & $\begin{array}{l}0.20 \\
0.18 \\
0.62\end{array}$ \\
\hline $\begin{array}{l}\text { Elk Island } \\
\text { Summer }\end{array}$ & $\begin{array}{l}\text { Secondary } \\
\text { Mobile } \\
\text { Area + Point }\end{array}$ & $\begin{array}{l}0.92 \\
0.037 \\
0.039\end{array}$ & $\begin{array}{l}0.95 \\
0.020 \\
0.034\end{array}$ & $\begin{array}{l}0 \\
0.20 \\
0.80\end{array}$ & $\begin{array}{l}0 \\
0.47 \\
0.53\end{array}$ & $\begin{array}{l}0 \\
0.41 \\
0.59\end{array}$ & $\begin{array}{l}0.14 \\
0.056 \\
0.80\end{array}$ \\
\hline
\end{tabular}

HCHO Formaldehyde, CCHO Acetaldehyde, ACRL Acrolein, BENZ Benzene, B124 1,2,4-Trimethylbenzene, BD13 1,3-Butadiene 
source group contributes the largest. In Vancouver, acrolein has considerably lower secondary and primary mobile proportions than the aliphatic aldehydes. Approximately half of the benzene is from primary mobile sources in the winter at both Hope and Vancouver.

In the summertime, the secondary contributions to the aldehydes increase and becomes the dominate source with the exception of acrolein at Vancouver where area/point sources still dominate. Primary mobile and area/point emissions are both important for benzene at both Hope and Vancouver. Primary mobile sources of 1,3-butadiene dominate at Hope in the winter and summer.

\subsubsection{Edmonton and elk island, Alberta}

In the winter, all three source groups contribute significantly to the aliphatic aldehydes at both Edmonton and Elk Island. Edmonton has higher direct mobile contributions and lower secondary contributions compared to the proportions at Elk Island. Acrolein has high area/ point emissions at both Edmonton and Elk Island in the winter. Mobile emissions contribute approximately half of benzene at Edmonton. At Elk Island, the area/point emissions are the dominate source of benzene. In Edmonton, the results indicate a large area/point source for 1,2,4-trimethylbenzene. This is consistent with a positive matrix factorization analysis performed for the Greater Edmonton Area by Mintz and McWhinney (2008).

In the summer, the secondary contributions to the aliphatic aldehydes dominate and the primary area/point emissions are small. Primary mobile emissions contribute $19 \%$ and $10 \%$ to formaldehyde and acetaldehyde in Edmonton in the summer. Primary mobile emissions contribute half to benzene in Edmonton and a lesser fraction at Elk Island.

\subsubsection{Toronto and Egbert, Ontario}

In the winter, the primary mobile emissions contribute $14-21 \%$ for the aliphatic aldehydes at Toronto and Egbert. Primary area/point aldehyde emissions are the largest group in Toronto and the secondary contributions are largest at Egbert even in the winter. Direct mobile emissions contribute $45-62 \%$ to the toxic hydrocarbons in the winter at Toronto and 46$50 \%$ in Egbert.

In the summer, primary mobile emissions are $12 \%$ and $6 \%$ for formaldehyde and acetaldehyde in Toronto, while area/point formaldehyde emissions are $17 \%$ and $9 \%$. Secondary sources for the aliphatic aldehydes dominate at Egbert ( $>95 \%)$. For the toxic hydrocarbons, both area/point and mobile emissions are important and are in similar proportions at Toronto and Egbert. Expectantly, mobile emission contributions are higher for 1,2,4-trimethylbenzene at Egbert compared to Toronto. This may be related to the large off-road mobile emission sources in the agricultural region around Egbert.

\subsubsection{Montreal and St. Anicet, Quebec}

In the winter, area/point sources are the largest source group at Montreal for the aliphatic aldehydes while at St. Anicet the secondary contributions are the largest. The mobile contributions are low in Montreal and St. Anicet, $12 \%$ to $25 \%$. The benzene contribution is approximately half from mobile emissions in Montreal and St. Anicet. Mobile emissions have a large contribution for 1,3-butadiene in Montreal (88\%) in the winter. In the summer, the mobile emissions are low for the aliphatic hydrocarbons. Area/point emission contributions are 
higher for Montreal than Toronto. Secondary contributions for St. Anicet dominate the aliphatic aldehydes in the summer $(>96 \%)$.

In the summer, mobile emissions for 1,3-butadiene dominate over the area/point sources with $93 \%$ and $7 \%$ respectively, in Montreal. For benzene and 1,2,4-trimethylbenzene, in the summer in Montreal, the emission groups are roughly equal. Mobile sources dominate for 1,2,4-trimethylbenzene at St. Anicet (90\%) in the summer.

Acrolein has a complex combination of primary emissions and secondary sources, many of which may be missing or inadequately resolved in the existing emissions data. For Toronto, the predicted direct mobile emission contributions are higher for acrolein than the aliphatic aldehydes but lower than the toxic hydrocarbons studied. For the other large cities, the mobile contribution was lower for acrolein than both the aliphatic aldehydes and hydrocarbons. The area/point emissions are the highest source for acrolein and thus may be well represented in inventory. The inventory may be underestimating the mobile emissions for acrolein or underestimating the chemistry forming acrolein in the summer. The inventory used here also does not include biomass burning emissions. Another possibility in the summer relates to the higher oxidant formation in the ambient air and the greater opportunity for oxidation of material on the DNPH adsorbent forming acrolein as a positive artifact.

In the summer, the spatial distribution for formaldehyde matches that of areas with large biogenic emissions (boreal forest of Canada, central California valley, and the southeast US plains). The large secondary contribution for formaldehyde is likely coming from the oxidation of biogenic emissions, in particular, isoprene $\mathrm{OH}$-oxidation which forms formaldehyde at high gas-phase yield (Millet et al., 2008). The spatial distribution for acetaldehyde is a combination of direct urban emissions and a regional background that correlates with the biogenic emissions. In Figure S6, the summertime model-averaged acetaldehyde surface concentration map is presented. The acetaldehyde direct emissions can be seen as hot spots over major cities, such as Chicago, but the regional background is also consistent with the satellite-derived leaf area index (Figure S7) associated with North American forests.

\subsection{Comparison to CMAQ modelling of toxic organic air pollutants over the US}

Luecken et al. (2012) investigated the fraction of formaldehyde and acetaldehyde production attributed to precursor VOC groups with the SAPRC-07 toxics mechanism in the CMAQ (Community Multi-scale Air Quality) model. For formaldehyde, in the winter, they found that the higher alkene group contributed the most for almost all US locations studied followed by ethene and propene species. In the U.S. National Emission Inventory, the higher alkene emissions were largely from mobile, storage/transport and waste release. In the Ontario emission inventory (Table 2), the higher alkene ( $>$ C3) emissions were area (largely agricultural), mobile (largely light-duty gasoline) and non-mobile (largely gasoline generator and yard equipment). Waste release was a significant source under the area emission category. The larger source from agriculture, relative to mobile, stems from the low population density for Ontario and the abundance of graze and farmland.

In the summer, for rural locations in the eastern US, isoprene was the dominant precursor to formaldehyde. For urban US locations, a complex precursor source distribution was predicted for formaldehyde by CMAQ. It should also be pointed out that summertime biogenic emissions of other non-terpene species (monoterpenes were in separate species named TERP and APIN) were lumped to the OLE1 and OLE2 species in SAPRC-07 toxics and were also important for formaldehyde production for rural (80-91\%) and surprisingly even some urban 
Table 2 Ontario Emission Inventory processed for the long change alkene model species $(>\mathrm{C} 3)$

\begin{tabular}{llll}
\hline Ontario Inventory & Emission Category & Subtotal & Total (tonnes/yr) \\
\hline On-road & LDGV & 2534 & $5364(24 \%)$ \\
& LDGT & 2112 & \\
& HDGV & 297 & \\
& HDDV & 274 & \\
& Motorcycle & 120 & \\
& LDDT & 17 & $9600(43 \%)$ \\
LDDV & 10 & \\
Off-road & Gasoline Generator & 1047 & \\
& Gasoline Lawn Mower & 399 & $5094(23 \%)$ \\
Gasoline Trimmers & 259 & \\
Area & Other & 7895 & \\
& Agriculture (Animals) & 3353 & \\
& Wood Industry & 468 & \\
& Petroleum Products Retail & 385 & \\
Waste & 359 & $588(2.6 \%)$ \\
Other Transport & Asphalt Paving & 186 & \\
& Other & 344 & \\
Point Sources & Aircraft & 529 & $1555(7.0 \%)$ \\
Grand Total & Train & 51 & 22,201 \\
\hline
\end{tabular}

sites in the US (8-53\%). It was beyond the capabilities of AURAMS to quantify the precursor contributions to formaldehyde chemical production.

It is interesting to compare the Canada and US national emission inventories for benzene in terms of summertime emissions. For Canada, the mobile emissions (1065 t) are a smaller relative contributor to total Canada-wide benzene $(6321 \mathrm{t})$ emissions at $17 \%$ of the total. For the US, the mobile emissions $(23,204 \mathrm{t})$ are the dominant contributor to total US-wide benzene emissions $(30,302 \mathrm{t})$, at $77 \%$ of the total. The higher mobile source contribution in the US compared to Canada is a combination of the larger population density in the US and the higher relative contribution of oil and gas extraction in Canada.

\section{Conclusions}

The toxic hydrocarbons measured by the NAPS network decreased by $10-15 \%$ over the 6 -yr. period studied. The major urban centers in eastern Canada showed even greater improvements in air quality for the toxic volatile hydrocarbons over the past decade. For example, in Montreal, benzene observed a drop in yearly-averaged concentrations between 2004 and 2010 from 8 to $2 \mu \mathrm{g} / \mathrm{m}^{3}$. This is consistent with improved vehicle exhaust after-treatment and cleaner fuels. However, some particular species have shown an increase in concentration at some industrial locations. For example, Port Moody has shown a steady increase in yearly-averaged acrolein between 2004 and 2010 from 0.03 to $0.09 \mu \mathrm{g} / \mathrm{m}^{3}$. This correlates with urban growth and increased ship traffic to the port during this time period.

We performed an AURAMS diagnostic evaluation for base year 2006, which yields a measure of model skill for predicting each toxic VOC. We validated the model in terms of 
studying spatial (urban vs rural sites, satellite-derived column density maps) and temporal (seasonal, day of week) trends. The model showed predictive skill for benzene which is encouraging given the diverse source distribution for benzene emissions. Predicted 1,2,4-trimethylbenzene showed a strong correlation with observations, but there is likely an emission under-estimation that is creating a negative model bias. AURAMS showed very good predictive skill for the aliphatic aldehydes, formaldehyde and acetaldehyde, but poor skill in predicting 1,3-butadiene and its oxidation product, acrolein.

The major goal of this study was to assess the mobile source contributions to the toxic VOCs for the urban centers across Canada. The mobile source contribution varied in a complex manner with each species for the different locations. For benzene, the mobile source apportionment was in the range $40-60 \%$ for major cities across Canada. The model predicted considerably lower mobile source contributions for rural locations in the Canadian prairies, where other area sources dominate (e.g. oil and gas). In contrast, in the US, the mobile sources for benzene dominate over other sources in both urban and rural sites with the exception of Gulf of Mexico shoreline due to the heavy petrochemical activity. For 1,2,4-trimethylbenzene, the mobile sources contribute to the majority of human outdoor exposure in the Canadian eastern cities. However, for Edmonton, the mobile source contribution to 1,2,4-trimethylbenzene is small compared to the area/point sources. For formaldehyde and acetaldehyde, a complex source distribution is found in the winter with all three groups (area and point, mobile and secondary) contributing significantly in Canadian cities. In the summer, secondary formation dominates even in urban areas, but the proportion of this secondary from biogenic and anthropogenic precursors has not been studied here. From the spatial distribution, it appears that the simple aldehydes are of biogenic carbon origin, although their production rate is likely enhanced by anthropogenic NOx emissions in urban areas.

The poor model performance for acrolein and 1,3-butadiene prevents robust conclusions regarding their source apportionment. The results suggest that a substantial proportion of their emissions may be missing (e.g. biomass burning) or inadequately speciated. It is recommended that future work compare the proton-transfer reaction mass spectrometry method to the canister and cartridge methods for acrolein and 1,3-butadiene. The PTR-MS technique may provide a better analytical method to calculate the acrolein and 1,3-butadiene emission factors from emission sources. This is a major effort, but is needed given the importance of acrolein as a toxic air pollutant.

Future work should also look for updates to the 1,2,4-trimethylbenzene emission factors from mobile sources, particularly exploring the US EPA MOVES emissions processing system. The impact of even lower model grid spacing, on the order of $2.5-\mathrm{km}$, should also be investigated for urban cities, where high density traffic data is available. For future work, the emission inventory base year (Canada NPRI 2006) should also be updated with projected emissions up to the current year.

Acknowledgments The authors are grateful to the Clean Air Regulatory Agency and Health Canada for funding. The authors are also appreciative of the US EPA for developing their national emission inventory, as well as their biogenic and anthropogenic emissions processing systems. The authors are supportive of the Environment Canada pollution data division for providing the Canadian National Pollution Release Inventory. The authors are also thankful to the entire AURAMS development team, especially C.S.'s mentor Paul Makar, research scientists Mike Moran and Wanmin Gong, associate scientists Sophie Cousineau and Mehrez Samaali and computer scientist, Balbir Pabla. The authors would also like to thank Elizabeth Galarneau and Paul Makar for their internal review of the manuscript. The authors acknowledge the free use of tropospheric $\mathrm{NO}_{2}$ column data from the OMI sensor from www.temis.nl. 
Open Access This article is distributed under the terms of the Creative Commons Attribution 4.0 International License (http://creativecommons.org/licenses/by/4.0/), which permits unrestricted use, distribution, and reproduction in any medium, provided you give appropriate credit to the original author(s) and the source, provide a link to the Creative Commons license, and indicate if changes were made.

\section{References}

Boersma K.F., Eskes H.J., Dirksen R.J., van der A.R.J., Veefkind J.P., Stammes P., Huijnen V., Kleipool Q.L., Sneep M., Claas J., Leitão J., Richter A., Zhou Y., Brunner D.: An improved tropospheric $\mathrm{NO}_{2}$ column retrieval algorithm for the ozone monitoring instrument. Atmos. Meas. Tech. 4, 1905-1928 (2011). doi:10. 5194/amt-4-1905-2011

Cahill T.M.: Ambient acrolein concentrations in coastal, remote and urban regions of California. Environ. Sci. Technol. 48(15), 8507-8513 (2014)

Carter W.P.L.: Development of the SAPRC-07 chemical mechanism. Atmos. Environ. 44(40), 5324-5335 (2010) CEPA, (1999) http://www.ec.gc.ca/lcpe-cepa/default.asp?lang=En\&n=26A03BFA-1.

Côté J., Gravel S., Méthot A., Patoine A., Roch M., Staniforth A.: The operational CMC-MRB global environmental multiscale (GEM) model. Part I: Design Considerations and Formulation. Mon. Wea. Rev. 126(6), 1373-1395 (1998)

Curren K.C., Dann T.F., Wang D.K.: Ambient air 1,3-butadiene concentrations in Canada (1995-2003): seasonal, day of week variations, trends, and source influences. Atmos. Environ. 40(1), 170-181 (2006)

Deeter M.N., Martínez-Alonso S., Edwards D.P., Emmons L.K., Gille J.C., Worden H.M., Sweeney C., Pittman J.V., Daube B.C., Wofsy S.C.: The MOPITT version 6 product: algorithm enhancements and validation. Atmos. Meas. Tech. 7, 3623-3632 (2014). doi:10.5194/amt-7-3623-2014

De Smedt I., Müller J.-F., Stavrakou T.: R. J. van der a, H. J. Eskes, and M. Van roozendael. Twelve years of global observations of formaldehyde in the troposphere using GOME and SCIAMACHY sensors. Atmos. Chem. Phys. 8(16), 4947-4963 (2008)

De Smedt I., Van Roozendael M., Stavrakou T., Müller J.-F., Lerot C., Theys N., Valks P., Hao N.: And R. J. van der a. Improved retrieval of global tropospheric formaldehyde columns from GOME-2/MetOp-a addressing noise reduction and instrumental degradation issues. Atmos. Meas. Tech. 5, 2933-2949 (2012)

Drummond J.R., Mand G.S.: The measurements of pollution in the troposphere (MOPITT) instrument: overall performance and calibration requirements. J. Atmos. Ocean. Technol. 13(2), 314-320 (1996). doi:10.1175/ 1520-0426(1996)013<0314:TMOPIT>2.0.CO;2

Galarneau E., Makar P.A., Zheng Q., Narayan J., Zhang J., Moran M.D., Bari M.A., Pathela S., Chen A., Chlumsky R.: PAH concentrations simulated with the AURAMS-PAH chemical transport model over Canada and the USA. Atmos. Chem. Phys. 14(8), 4065-4077 (2014)

Gong S.L., Barrie L.A., Blanchet J.-P., von Salzen K., Lohmann U., Lesins G., Spacek L., Zhang L.M., Girard E., Lin H., Leaitch R., Leighton H., Chylek P., Huang P.: Canadian Aerosol Module: A size-segregated simulation of atmospheric aerosol processes for climate and air quality models 1 . Module development. J. Geophys. Res. D: Atmos. 108(1), AAC 3-1-AAC 3-16 (2003)

Gong W., Stroud C.A., Zhang L.: Cloud processing of gases and aerosols in air quality modeling. Atmosphere. 2 (4), 567-616 (2011)

Heist D., Isakov V., Perry S., Snyder M., Venkatram A., Hood C., Stocker J., Carruthers D., Arunachalam S., Owen R.C.: Estimating near-road pollutant dispersion: A model inter-comparison. Transp. Res. Part D: Transp. Environ. 25, 93-105 (2013)

Hutzell W.T., Luecken D.J., Appel K.W., Carter W.P.L.: Interpreting predictions from the SAPRC07 mechanism based on regional and continental simulations. Atmos. Environ. 46, 417-429 (2012)

Kelly J., Makar P.A., Plummer D.A.: Projects of mid-century summer air-quality for North America: effects of changes in climate and precursor emissions. Atmos. Chem. Phys. 12, 5367-5390 (2012)

Levelt P.F., van den Oord G.H.J., Dobber M.R., Mälkki A., Visser H., de Vries J., Stammes P., Lundell J.O.V., Saari H.: The ozone monitoring instrument. IEEE Trans. Geosci. Remote Sens. 44, 1093-1101 (2006)

Logan J.A.: An analysis of ozonesonde data for the troposphere: Recommendations for testing 3-D models and development of a gridded climatology for tropospheric ozone. Journal of Geophysical Research: Atmospheres. 104(D13) art. no. 1998JD100096, 16115-16149 (1999)

Luecken D.J., Hutzell W.T., Strum M.L., Pouliot G.A.: Regional sources of atmospheric formaldehyde and acetaldehyde, and implications for atmospheric modeling. Atmos. Environ. 47, 477-490 (2012)

Luecken D.J., Hutzell W.T., Gipson G.L.: Development and analysis of air quality modeling simulations for hazardous air pollutants. Atmos. Environ. 40(26), 5087-5096 (2006) 
Makar P.A., Bouchet V.S., Nenes A.: Inorganic chemistry calculations using HETV - a vectorized solver for the SO4 2-NO3 -NH4 + system based on the ISORROPIA algorithms. Atmos. Environ. 37(16), 2279-2294 (2003a)

Makar P.A., Moran M.D., Scholtz M.T., Taylor A.: Speciation of volatile organic compound emissions for regional air quality modeling of particulate matter and ozone. J. Geophys. Res. D: Atmos. 108(2), ACH 2-1ACH 2-51 (2003b)

Makar P.A., Gong W., Milbrandt J., Hogrefe C., Zhang Y., Curci G., Zakbar R., Im U., Galmarini S., Gravel S., Zhang J., Hou A., Pabla B., Cheung P., Bianconi R.: Feedbacks between air pollution and weather, part 1: effects on weather. Accepted, Atmospheric Environment (2014a)

Makar, P.A., Gong, W., Hogrefe, C., Zhang, Y., Curci, G., Zakbar, R., Milbrandt, J., Im, U., Galmarini, S., Balzarini, A., Baro, R., Bianconi, R., Cheung, P., Forkel, R., Gravel, S., Hirtl, M., Honzak, L., Hou, A., Jimenez-Guerrero, P., Langer, M., Moran, M.D., Pabla, B., Perez, J.L., Pirovano, G., San Jose, R., Tuccella, P., Werhahn, J., Zhang: Feedbacks between Air Pollution and Weather, Part 2: Effects on Chemistry. Accepted, Atmos. Environ.. (2014b).

Makar P.A., Nissen R., Teakles A., Zhang J., Zheng Q., Moran M.D., Yau H., Dicenzo C.: Turbulent transport, emissions and the role of compensating errors in chemical transport models. Geosci. Model Dev. 7(3), 1001$1024(2014 c)$

McLinden C.A., Fioletov V., Boersma K.F., Kharol S.K., Krotkov N., Lamsal L., Makar P.A., Martin R.V., Veefkind J.P., Yang K.: Improved satellite retrievals of NO2 and SO2 over the Canadian oil sands and comparisons with surface measurements. Atmos. Chem. Phys. 14(7), 3637-3656 (2014)

MacDonald A.M., Anlauf K.G., Leaitch W.R., Chan E., Tarasick D.W.: Interannual variability of ozone and carbon monoxide at the whistler high elevation site: 2002-2006. Atmos. Chem. Phys. 11(22), 11431-11446 (2011)

Mintz R., McWhinney R.D.: Characterization of volatile organic compound emission sources in fort Saskatchewan, Alberta Using principal Component Analysis. J. Atmos. Chem. 60, 83-101 (2008)

NPRI (2006) https://www.ec.gc.ca/inrp-npri/

Rouleau M., Egyed M., Taylor B., Chen J., Samaali M., Davignon D., Morneau G.: Human health impacts of biodiesel use in on-road heavy duty diesel vehicles in Canada. Environ. Sci. Technol. 47(22), 13113-13121 (2013)

Richtmyer, R. D.,: Difference methods for initial value problems. Krieger Pub. Co., Malabar, Fla., 405 pp. (1994).

Sandu A., Sander R.: Technical note: Simulating chemical systems in Fortran90 and Matlab with the Kinetic PreProcessor KPP-2.1. Atmos. Chem. Phys. 6(1), 187-195 (2006)

Stroud C.A., Morneau G., Makar P.A., Moran M.D., Gong W., Pabla B., Zhang J., Bouchet V.S., Fox D., Venkatesh S., Wang D., Dann T.: OH-reactivity of volatile organic compounds at urban and rural sites across Canada: evaluation of air quality model predictions using speciated VOC measurements. Atmos. Environ. 42(33), 7746-7756 (2008)

Stroud C.A., Makar P.A., Moran M.D., Gong W., Gong S., Zhang J., Hayden K., Mihele C., Brook J.R., Abbatt J.P.D., Slowik J.G.: Impact of model grid spacing on regional- and urban- scale air quality predictions of organic aerosol. Atmos. Chem. Phys. 11(7), 3107-3118 (2011)

Young T.R., Boris J.P.: A numerical technique for solving stiff ordinary differential equations associated with the chemical kinetics of reactive-flow problems. J. Phys. Chem. 81(25), 2424-2427 (1977) 